Kyoto University,

Graduate School of Economics

Research Project Center Discussion Paper Series

An Analysis of CDS Market Liquidity by the Hawkes Process

\author{
Masahiko Egami \\ Yasuyuki Kato \\ Tomochika Sawaki
}

Discussion Paper No. E-13-001

Research Project Center

Graduate School of Economics

Kyoto University

Yoshida-Hommachi, Sakyo-ku

Kyoto City, 606-8501, Japan

June 2013 


\title{
An Analysis of CDS Market Liquidity by the Hawkes Process
}

\author{
Masahiko Egami Yasuyuki Kato Tomochika Sawaki
}

\begin{abstract}
We study the credit default swap (CDS) markets in the U.S. and Japan, focusing on bid-ask spreads which are closely related to the liquidity of the markets. Since bid-ask spreads dramatically surged during the financial crisis (2008-2009) and the market became very illiquid, it is crucially important to investigate how bid-ask spreads fluctuate. In this paper, not only do we make dynamic analysis of the bid-ask spreads in both countries but propose a model to predict bid-ask spreads via the self-exciting intensity process (the Hawkes process).
\end{abstract}

Key words: CDS contract; liquidity; bid-ask spread; the Hawkes process; self-exciting processes, financial crisis, credit risk.

JEL Classification: G10, G17, G21

\section{Introduction}

The credit default swap (CDS) contract is a major single-name credit derivative and serves as the building block for many other credit derivative instruments. We refer to O'Kane [13] for the definition of the CDS contract: A CDS is a bilateral over-the-counter contract whose purpose is to protect one party, the protection buyer, from the loss from par on a specified face value of bonds, or loans following the default of their issuer. The CDS markets expanded rapidly during the first half of the last decade. We have witnessed, however, a huge pike of bid-ask spreads in the U.S. CDS market during the financial crisis period. It is said that the liquidity evaporated and the market participants had difficulty in completing 
their transactions. See the bid-ask spreads ("BAS" hereafter) and the number of quotes in the U.S. and Japan CDS markets in Figure 1.

Figure 1: Daily averages of BAS and Quote numbers
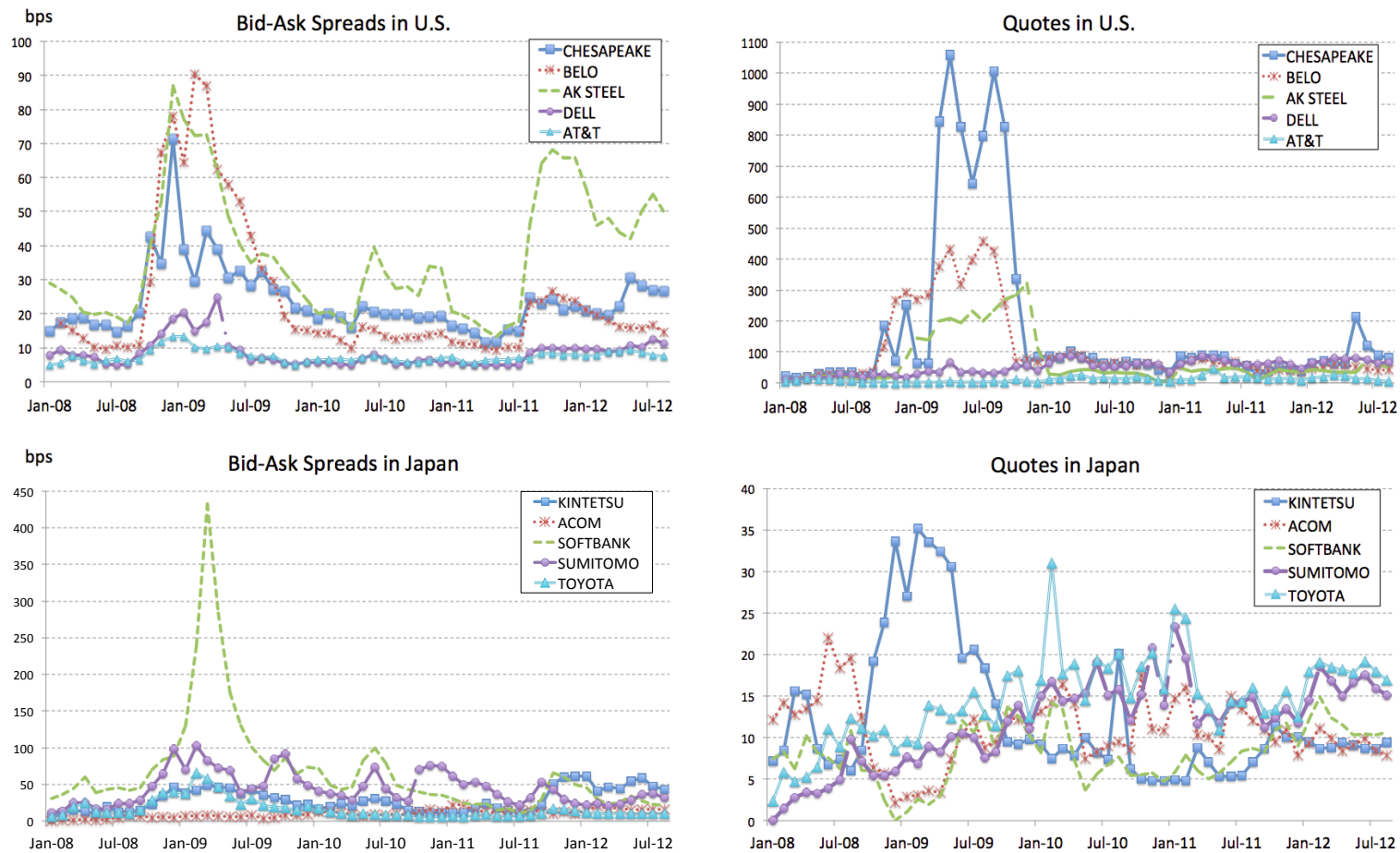

We shall focus on BAS in this paper for the following reasons: First, Figure 1 shows that, during the crisis period, BAS increased drastically in both U.S. and Japan. It is obvious that the variability of BAS is closely related to the liquidity of the CDS markets. In this sense, we believe that it is crucial to understand in what way the spreads fluctuate, sometimes vastly, and to know mechanism behind it. Second, in view of Longstaff et al. [10], the CDS premia are largely explained by credit component, so the information about liquidity of the market is mainly contained in BAS. Of course, however, market makers often bear underling credit risk during their holding period until they sell the contract. Thus, if the default probability of the underling loan/bond goes up, they may end up with holding an open position, so that BAS also contains, to some extent, credit risk information. But again, this increased credit risk level is promptly reflected in the rise of CDS premia, and hence the credit part of BAS seems to vanish soon or later, as long as there is enough liquidity is provided in the market. Also, it is worth mentioning that Roll [15] claims in the study of the stock market that BAS are efficiently determined by market makers through their functioning as liquidity providers to the market. We therefore investigate 
Table 1: Comparison of the CDS indices between U.S. and Japan

\begin{tabular}{c|ccc} 
(million $\$, 2009)$ & gross notional & net notional & \# contracts \\
\hline CDX.NA.IG SERIES 9 & $1,324,894$ & 75,213 & 22,334 \\
iTraxx Japan SERIES 11 & 13,032 & 1,448 & 1,050
\end{tabular}

\begin{tabular}{c|c} 
(million \$, 2010) & gross notional \\
\hline Japan & $1,116,900$ \\
World & $30,261,000$
\end{tabular}

the CDS markets in the U.S. and Japan and fit some models to explain fluctuations of the BAS.

Studying both the U.S. and Japan markets is beneficial because the degree of market efficiency differ. Table 1 is a comparison of the contracts of the CDS indices, indicating a big difference in size.

In particular, an observation of time series data of CDS premia reveals the following: Larger and more frequent price swings have been recorded in the U.S. market. Lower-grade names are more frequently traded than investment-grade names in the U.S., while trade volumes in higher-grade names are far greater (than lower-grade) in Japan. Since the Japanese market is in its early period, a full utilization of the market to trade credit risks may have not been accomplished. It seems instructive to analyze the "developed" and "developing" markets simultaneously since one can understand the process of market evolution as well as the similarity and difference of the two markets.

Now let us take a look at Figure 1 again for the time series data of BAS and the numbers of quotes. First, the number of quotes are far greater in the U.S. market compared to Japan. In both countries, as we know, there are high peaks in the quote numbers and BAS during the financial crisis $(2008 \sim 2009)^{1}$. The relationship between these two variables needs more investigation: we shall also see the non-crisis periods in developing a model that predicts BAS.

We shall briefly mention main results of this paper:

(1) In Section 1.1, by simple regressions, changes in BAS of U.S. companies' CDS contracts can be explained both by their respective bid prices and the economic factors that surround the companies. This is not the case in Japan, where the CDS market does not fully incorporate general and/or company-specific economic factors. The difference in the market efficiency may be attributable to this contrasting phenomenon.

\footnotetext{
${ }^{1} \mathrm{~A}$ special mention is necessary for a huge upsurge in the bid-ask spread of Softbank contract: it is due to its announced merger of the struggling mobile provider, Willcom.
} 
(2) We observe time-series data of bid price and BAS in Section 2.1. By the Grander causality test, we find that the two variables have causality in both directions: Bid price is a cause of BAS changes and vice versa. Moreover, there exists a "reversal" phenomenon in BAS changes. If one observes an increase in BAS at some point, then in the next period BAS has a tendency to decline.

(3) Over a long period (Jan 2002 through 2010) there is a large variability in correlation coefficients between bid prices and BAS (in Section 2.2).

(4) We construct a model to explain BAS movements based on quote numbers. The main purpose of this modeling is to predict near-future BAS, which we believe is of practical use. We observe a short-run surge and fall in the correlation coefficient between the quote numbers and BAS. More specifically, we attempt to model the number of quotes by a self-exciting intensity process (or the Hawkes process). The term "self-exciting" implies that the intensity of quote arrivals to the market makers increases as quote numbers themselves increase. We then use the time-changed Brownian motion to model BAS fluctuations. The new clock here is arrival times of quotes. See (3.1) (3.3). The prediction results shown in Section 3 are very promising. From what we observe in the two performance tests, the Hawkes process-based prediction does pretty well, whether it is used for the U.S. or Japanese market, and whether it is used for higher or lower credit rating companies.

There are numerous empirical studies on how CDS prices are determined. Blanco et al. [2] find the impact of firm-specific stock returns is stronger on CDS price changes than on corporate bond spread changes. Norden and Weber [11] report, among other things, that the lower company's credit rating, the more sensitive CDS prices to its stock price, and that the CDS market contributes more to price discovery than the bond market and this effect is stronger for U.S. than for European companies. Acharya and Johnson [1] provide empirical evidence that there is an information flow from the credit default swap markets to equity markets and the flow is concentrated on days with negative credit news. More specific to liquidity, Longstaff et al. [10] report that the majority of the corporate spread is due to default risk (rather than liquidity risk), which result holds for all rating categories. Moreover, they find the nondefault component is time varying and strongly related to measures of bond-specific illiquidity as well as to macroeconomic measures of bond market liquidity. In this vein, more recently, Bühler and Trapp [3] propose a reduced-form model to decompose bond spreads and CDS premia into three components (pure credit risk, liquidity risk and a component measuring the reltion between credit and liquidity risk components). Ericsson and Renault [6] report that in finite maturity debt markets, there exist decreasing and convex term structures of liquidity. The Hawkes process we shall employ in this paper is proposed by Hawkes [8]. In the finance literature, there are a number of papers that model 
certain economic variables by using the Hawkes processes. For example, Hewlett [9] uses for order arrivals in the stock market and Errais et al. [7] use for default events in a credit-related portfolio of large size.

We mention the data we use in this paper. For the regression analysis in section 1.1, vector autoregression in section 2.1 and DCC-GARCH in section 2.2.1, we take all the information including bid prices and bid-ask spreads from DATASTREAM by Thomson Reuters. The period is January 2003 to September 2010. Since the quote numbers are not available in DATASTREAM we subscribe, we obtain quote numbers and bid-ask spreads from Markit Group Limited. The period is January 2008 to August 2012. (Note that the data of quote numbers are available only after January 2008.) Quote numbers are used (along with bid-ask spreads) for DCC-GARCH in section 2.2.2 and for the analysis based on the Hawkes process in sections $3.1 \sim 3.2$. Note that all the tables from the statistical analysis are placed in Appendix.

\subsection{Preliminary Regression Analysis}

Bid vs Economic Variables: We shall take a look at "Bid" price of the CDS via a simple regression. This is because the BAS may be influenced by bid prices.

$\Delta(\operatorname{Bid})_{t}=a_{0}+b_{1} \Delta(\text { Interest })_{t}+b_{2} \Delta(\mathrm{VI})_{t}+b_{3} \Delta($ Volume $)$

$$
+c_{1} \Delta(\text { StockPrice })_{t}+c_{2} \Delta(\text { StockSigma })_{t}+c_{3} \Delta(\text { StockVol })_{t}+d_{1}(\text { Crisis })_{t}+\epsilon_{t} .
$$

The objective variable is $\Delta(\mathrm{Bid})_{t}$ is the difference in bid prices at time $t$. The first three valuables are, in essence, related to macro-economic situations: $\Delta$ (Interest $)_{t}$ is the change in yield rates of $10-$ year government bonds, $(\mathrm{VI})_{t}$ is the change in VIX (U.S.) or Nikkei Volatility Index, $\Delta(\text { Volume })_{t}$ is the change in trading volumes in the Dow Jones Index or TOPIX. The next three valuables are specific to the underlying loan/bond issuer: $\Delta$ (StockPrice $)_{t}$ is the change in the issuer's stock price, $\Delta$ (StockSigma) is the change in the stock price volatility from the last 4 prior weeks, and $\Delta$ (StockVolume) is the change in trading volume of the issuer's stock. Finally, we attach a dummy variable (Crisis) taking a value of zero if $t$ is prior to September 15, 2009 and of unity if $t$ is after that date. The result is summarized in Table 3 in the Appendix.

The third and fourth columns of the upper and lower panel are the adjusted $\mathrm{R}^{2}$ of regression (1.1) for the U.S. and Japanese markets, respectively. In the U.S. market, the average (over 20 names) $\mathrm{R}^{2}$ 's are 0.1308 in the one-year CDS and 0.1988 in the five-year CDS. Several variables such as $\Delta(\mathrm{VI})_{t}$,

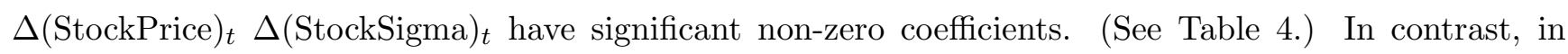
Japan, the average (over 20 names) $\mathrm{R}^{2}$ are 0.01324 in one year CDS and 0.03966 in five year contract, far 
below the U.S. counterparts. The three valuables that seem to have significant impact in the U.S. market are not the cases in Japan. To get more information, we separate Japanese corporate names into two categories: high credit rating (A- or greater by the Japanese rating agency $\mathrm{R} \& \mathrm{I}$ ) and low credit rating (BBB + or lower). The average $\mathrm{R}^{2}$ 's are improved in the high rating category: one year CDS, 0.02471 and five year 0.05504, while the low rating category become even worse: one year CDS, 0.001767 and five year, 0.02429 .

It is clear that part of variations of the bid prices in the U.S. market can be explained by the microand macroeconomic factors. But in Japan, bid prices are not so well explained by these factors, especially in the low rating category. In both markets, the $\mathrm{R}^{2}$ are better in five year contracts than one year.

BAS vs Bid: The next question is to what extent BAS can be explained by bid prices:

$$
\Delta(\mathrm{BAS})_{t}=a_{0}+a_{1} \Delta(\mathrm{Bid})_{t}+d_{1}(\text { Crisis })+\epsilon_{t}
$$

The results are shown in the fifth and sixth columns of Table 3. The averages (over 20 names) in Japan are 0.09647 ( 1 year) and 0.1093 ( 5 year) with significant non-zero estimates of $a_{1}$ in almost all names. In the U.S. market, the numbers are 0.08024 (one year) and 0.16369 (five year) with significant non-zero estimates, too.

BAS vs (Bid + Economic Variables): A natural question is then if we add six variables in (1.1) to the estimation (1.2), can we get any improvement?

$\Delta(\mathrm{BAS})_{t}=a_{0}+a_{1} \Delta(\mathrm{Bid})_{t}+b_{1} \Delta(\text { Interest })_{t}+b_{2} \Delta(\mathrm{VI})_{t}+b_{3} \Delta($ Volume $)$

$$
+c_{1} \Delta(\text { StockPrice })_{t}+c_{2} \Delta(\text { StockSigma })_{t}+c_{3} \Delta(\text { StockVol })_{t}+d_{1}(\text { Crisis })_{t}+\epsilon_{t} .
$$

To answer the question, we conduct the partial F-test: See the last two columns of Table 3. The marginal contribution of the six variables to $\mathrm{R}^{2}$ is tested. In the U.S. market, the six additional variables have statistically significant contribution in 9 names out of 20 names at $5 \%$ significant level. Especially, 7 names (in 1 year contracts) and 6 names (in 5 year) out of 10 names in low rating category show significant improvement. Since, in the U.S., the CDS market is more liquid in the lower grade category and is used for hedging credit risk of these companies, the level of BAS incorporates many factors. Norden and Weber [11] report that the higher the credit risk, the more sensitive to stock return fluctuations the CDS price becomes. Our result here is consistent with this: Since a lower-graded company is more exposed to "flight to liquidity", market makers may promptly respond to changes in general and/or company-specific factors by widening and shrinking BAS. In Japan, in contrast, only in 4 names (mostly higher grade) out 
of 20 names do we observe marginal improvements. The latter result is consistent with the regression result of (1.1).

As a consequence of this test, we may say that in the U.S. market, BAS is explained both by bid prices and by micro-and macroeconomic factors, while in the Japanese market, BAS is explained only by bid prices. Since the CDS market in Japan is in its incipient stage, BAS are charged for some reasons that do not necessarily reflect the general economic or company specific factors. In particular, in the lower grade category, this phenomenon is more apparent.

\section{Time Series Analysis}

\subsection{Autoregressive Model}

To make a further comparison between the U.S. and Japanese markets and to better understand the interaction between bid prices and BAS, we consider the following vector autoregression (VAR): We tested 20 names in each market, using the data from Jan-2003 to Sep-2010.

$$
\left\{\begin{array}{l}
\Delta(\mathrm{Bid})_{t}=a_{1}+b_{11} \Delta(\mathrm{Bid})_{t-1}+b_{12} \Delta(\mathrm{BAS})_{2, t-1}+\epsilon_{1, t} \\
\Delta(\mathrm{BAS})_{t}=a_{2}+b_{21} \Delta(\mathrm{Bid})_{t-1}+b_{22} \Delta(\mathrm{BAS})_{2, t-1}+\epsilon_{2, t}
\end{array}\right.
$$

where $\left(\begin{array}{c}\epsilon_{1, t} \\ \epsilon_{2, t}\end{array}\right)$ has the variance-covariance matrix $\left(\begin{array}{cc}\sigma_{1}^{2} & \rho \sigma_{1} \sigma_{2} \\ \rho \sigma_{1} \sigma_{2} & \sigma_{2}^{2}\end{array}\right)$. The results are shown in Table 5. Let us first see the signs of each coefficient. The most striking feature is that the sign of $b_{22}(\Delta \mathrm{BAS} \rightarrow$ $\triangle \mathrm{BAS})$ is negative in both markets and in both 1 year and 5 year contracts, while the sign of $b_{21}(\Delta \operatorname{Bid} \rightarrow$ $\triangle \mathrm{BAS}$ ) is positive in most of the cases. Hence if one observes an increase in CDS price at some period, the next period is likely to witness an increase in BAS. Regarding this point, it is interesting to observe 5 out of 20 U.S. companies have negative signs on $\Delta$ (Bid) variables in regression (1.3), while 9 out of 20 U.S. companies have positive signs on the variable. See Table 4.

On the other hand, if one observes an increase in BAS at some point, then one may see a decline in BAS in the next period. This "reversal" property checks BAS not to keep rising, so BAS remains in reasonable stable levels.

Another point to make is that there exists strong Granger causality from $\Delta \mathrm{BAS}$ to $\Delta \mathrm{Bid}$ in 11 names (6 names) out of 20 in the US 1 year (resp. 5 year) CDS market. There are also 9 names in 1 year contracts and 8 names in 5 year contracts in Japanese market. This causality is a bit counterintuitive. A possible explanation is that the market participants may take BAS into consideration when they 
determine absolute levels of credit risk (i.e., bid price). To get more insights into this phenomenon, we conducted more Grander causality tests including quote numbers (Quotes, hereafter): See Table 6 where we test $\Delta$ (Bid) $\rightleftarrows \Delta$ (Quotes) and $\Delta$ (BAS) $\rightleftarrows \Delta$ (Quotes) and report the $F$-statistics. The causality observed here is less significant than the causality from $\Delta$ (BAS) to $\Delta$ (Bid). Hence if we look at a long time period, the relationship between the bid prices and BAS is stronger than that between Quotes and BAS.

\subsection{DCC-GARCH Model}

\subsubsection{BAS-Bid}

Next, we study dynamic correlation models with $\operatorname{GARCH}(1,1)$, following the method proposed by Engel [5]. A brief explanation of this model is as follows: Defining an appropriate filtration $\left(\mathcal{F}_{t}\right)_{t \geq 0}$, the $n$ dimensional vector at time $t, y_{t}$ is modeled by $y_{t}=\mu_{t}+a_{t}$ where $\mu_{t}=\mathbb{E}\left(y_{t} \mid \mathcal{F}_{t-1}\right)$ and $a_{t}=H_{t}^{1 / 2} v_{t}$ with $v_{t} \sim$ i.i.d $N\left(0, I_{n}\right)$. We then have $H_{t}=\operatorname{Cov}\left(a_{t} \mid \mathcal{F}_{t-1}\right)$. Now $H_{t}$ is in turn modeled by

$$
H_{t}=D_{t} R_{t} D_{t}
$$

where $R_{t}=\left(\rho_{i j, t}\right)_{n \times n}$ is a positive definite matrix, $D_{t}=\operatorname{diag}\left\{\sqrt{h_{11, t}}, \ldots, \sqrt{h_{n n, t}}\right\}$. Moreover, $R_{t}$ is

$$
R_{t}=\operatorname{diag}\left(Q_{t}\right)^{-\frac{1}{2}} Q_{t} \operatorname{diag}\left(Q_{t}\right)^{-\frac{1}{2}}
$$

where $Q_{t}$ satisfies

$$
Q_{t}=\left(1-\theta_{1}-\theta_{2}\right) \bar{Q}+\theta_{1} \epsilon_{t-1} \epsilon_{t-1}^{\prime}+\theta_{2} Q_{t-1} .
$$

Here $\epsilon_{t}$ is the standardized innovation vector with $\epsilon_{t}=D_{t}^{-1} a_{t}$ and $\bar{Q}$ is the unconditional correlation matrix of $\epsilon_{t}$. For $Q_{t}$ to be positive definite, a sufficient condition is that $\theta_{1}, \theta_{2}>0, \theta_{1}+\theta_{2} \leq 1$.

We fit the above DCC-GARCH $(1,1)$ to 10 names (5 each in the U.S. and Japan)

(1) Bid - BAS: from Jan-2003 to Sep-2010 (Figure 2) and

(2) BAS - Quotes: from Jan-2008 to Aug-2012 (Figure 3). ${ }^{2}$

First, from Figure 2, we observe large variability in correlation coefficients (between Bid price and BAS) in general. This is consistent with the causal relationship between the two variables confirmed in Table 5. In the U.S. market, however, the fluctuations seem greater as the credit rating goes worse. Compare AT\&T with credit rating A- and Chesapeake Energy (BB-). In contrast, in the Japanese

\footnotetext{
${ }^{2}$ The quote numbers are available only after January 2008.
} 

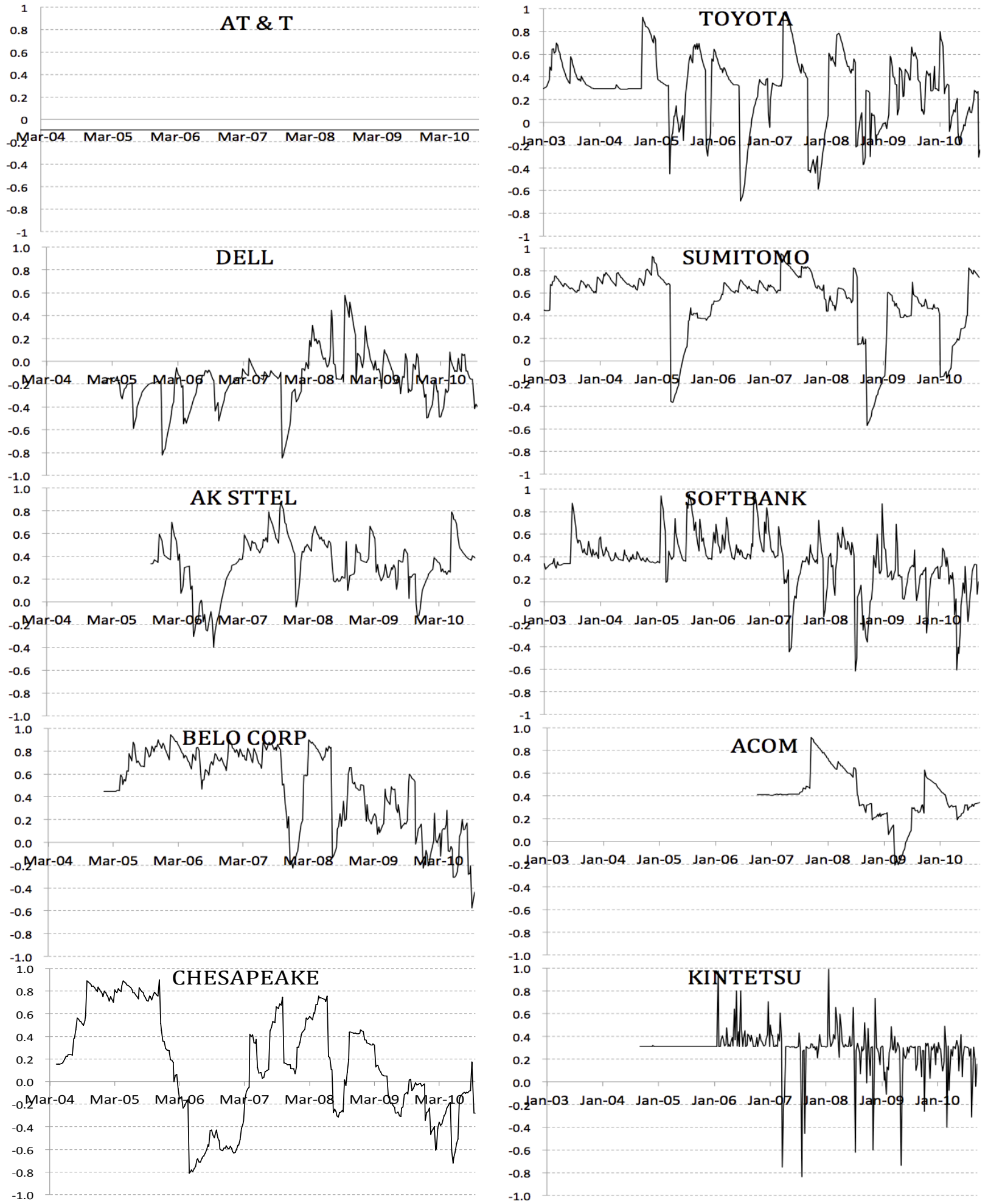

Figure 2: Estimated dynamic correlations between BAS-Bid Price 

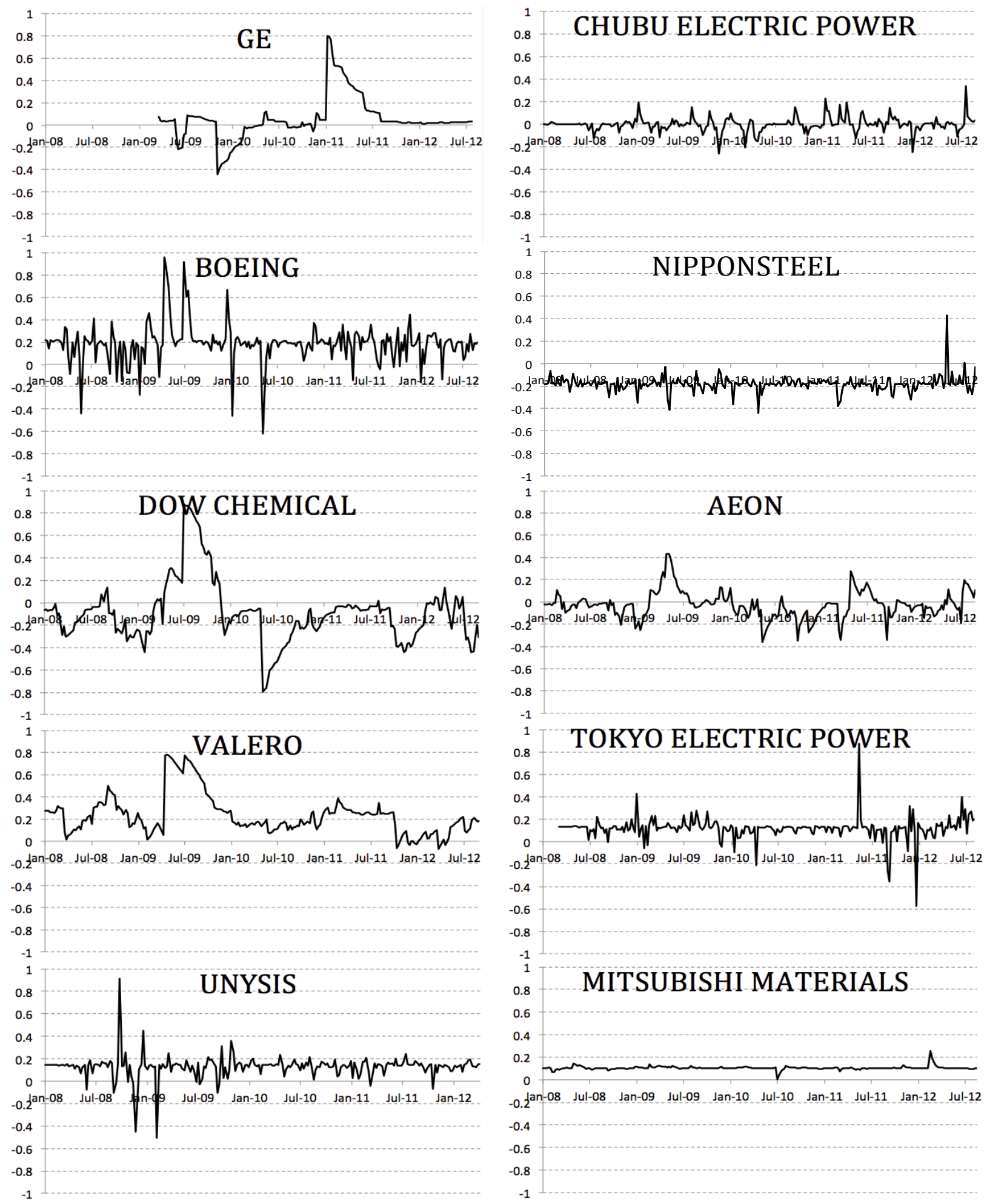

Figure 3: Estimated dynamic correlations between BAS and Quotes 
market, irrespective of credit ratings, there exists a large variability across the names. This big swing of correlation coefficients indicate that it is unlikely that there exists a stable (over time) linear relationship between the two variables.

\subsubsection{BAS-Quotes}

Next, from Figure 3, we see that the variability in correlation coefficients (between Quote numbers and BAS) is not as large as in the previous pair. This may explain weaker causality relationship between the two variables. (Recall the results in Table 6.) But there are sharp pikes occasionally. See for example Boeing (A): the correlation coefficient is very low around 0.2 in most of the times but it jumped up to 0.8 from time to time.

For the purpose of predicting BAS, we believe that short-run analytical tool is of more practical use. As experienced in the recent financial crisis, liquidity crisis would break out all of sudden. The cost to hedge credit risks could surge in the short run. Thus, it would be helpful if one could foresee near-future BAS levels when trying to load and/or unload credit risks. From this point of view, although the causality relationship is stronger (at least in the long run) between Bid price and BAS, we shall concentrate on the Quote numbers to explain BAS. The occasionally observed high level of correlation between Quote numbers and BAS may provide us with a useful tool to predict liquidity levels in the short run.

\section{The Hawkes Process}

\subsection{Specification}

We build models to estimate and predict bid-ask spreads (BAS) in two steps: Let $M$ be a standard Poisson random measure on $\mathbb{R}_{+} \times \mathbb{R}_{+}$defined on a probability space $(\Omega, \mathcal{F}, \mathbb{P})$ where $\left(\mathcal{F}_{t}\right)_{t \geq 0}$ is the augmented filtration generated by $M$. Let $B$ be a standard Browinian motion independent of $M$. Define $\lambda$ and $N$ by setting $N_{0}=0, \lambda_{0}=a$ and

$$
\begin{aligned}
& \lambda_{t}:=a e^{-c t}+\int_{(0, t)} b e^{-c(t-s)} \mathrm{d} N_{s}, \quad t>0, \\
& N_{t}:=\int_{[0, t] \times \mathbb{R}_{+}} M(\mathrm{~d} s, \mathrm{~d} z) 1_{\left(0, \lambda_{s}\right]}(z), \quad t>0,
\end{aligned}
$$

where $a, b, c \in(0, \infty)$ are constants. Refer this formulation to Çinlar[4]. It is called self-exciting (or the Hawkes process) in the sense that $\lambda_{t}$ is affected by the path of $N$ over $(0, t)$. The impact of $N$ decays exponentially over time with rate $c$ and the reversion level is $a$. The sensitivity parameter $b$ takes care of 
the impact on $\lambda$ when $N$ increases. In our context, $N$ is for the number of quotes and $\lambda$ is the intensity of arrivals of these quotes. Moreover, we model the evolution of BAS, $X=\left\{X_{t}, t \geq 0\right\}$, by the Brownian subordination of $N$ :

$$
X_{t}:=X_{0} \exp \left(\left(\alpha-\frac{\beta^{2}}{2}\right) N_{t}+\beta B_{N_{t}}\right) .
$$

Since $N$ is an increasing Lévy process and $B$ is a Brownian motion in $\mathbb{R}$ independent of $N, X$ is also a Lévy process (Theorem VII.6.2.[4]). The simple idea is the following: In Section 2.2 we observe when there are enough numbers of quotes, the correlation between BAS and quote numbers becomes instantaneously higher and the changes in BAS are not uniform in the real time. Accordingly, this time-change seems natural. That is, BAS changes when there arrives a quote. Figure 4 show some sample paths of the intensity process $\lambda_{t}$ and the corresponding counting process $N_{t}$. Figure 5 are some sample paths of the intensity process $\lambda_{t}$ with the corresponding Brownian subordination $X_{t}$.
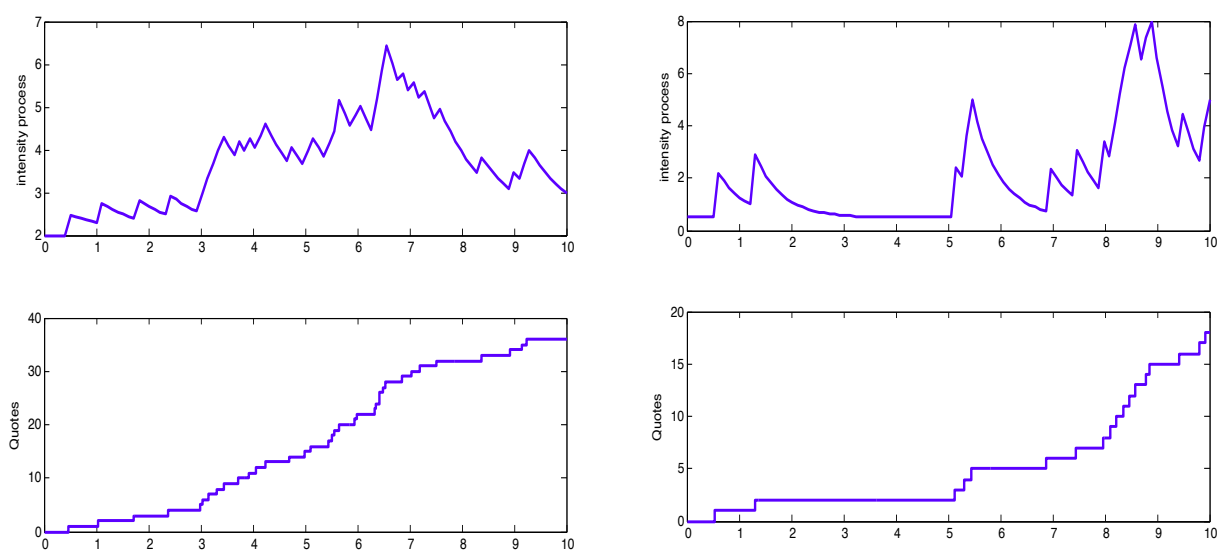

Figure 4: Hawkes process

Top: intensity process, Bottom: accumulating Quotes; left: $\mathrm{t}=10, \mathrm{a}=2.0, \mathrm{~b}=0.5, \mathrm{c}=1.0$, right:

$$
\mathrm{t}=10, \mathrm{a}=0.5, \mathrm{~b}=2.0, \mathrm{c}=2.0
$$

Our estimation of the parameters in (3.1) is based on Ozaki [14]. Let $t_{1}, t_{2}, \ldots, t_{n}$ be the times of occurrence, the log-likelihood function of $N_{t}$ is written

$$
\log L\left(t_{1}, t_{2}, \ldots, t_{n} \mid \theta\right)=-\int_{0}^{T} \lambda(t \mid \theta) \mathrm{d} t+\int_{0}^{T} \log \lambda(t \mid \theta) \mathrm{d} N_{t}
$$

where $[0, T]$ is the observation period. In the specification of (3.1), it becomes

$$
\log L\left(t_{1}, t_{2}, \ldots, t_{n} \mid \theta\right)=-a t_{n}+\sum_{i=1}^{n} \frac{b}{c}\left(e^{-c\left(t_{n}-t_{i}\right)}-1\right)+\sum_{i=1}^{n} \log \left(a+\sum_{j}^{i} e^{-c\left(t_{i}-t_{j}\right)}\right) .
$$



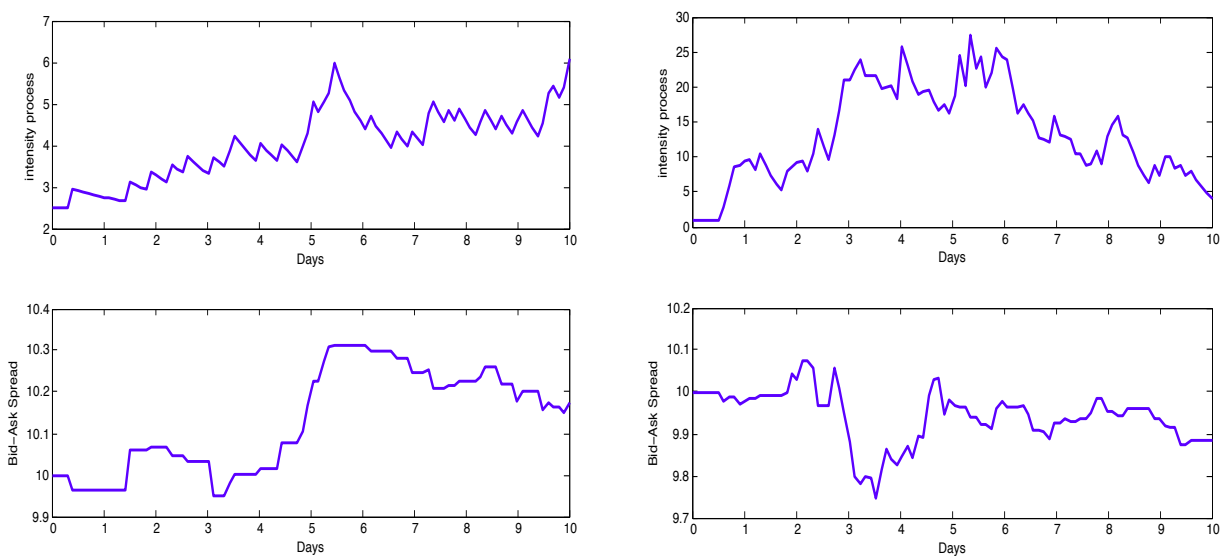

Figure 5: Brownian Subordination

Top: intensity process, bottom: Bid-Ask Spread ( $\alpha=0.0005, \beta=0.003)$, left: $\mathrm{t}=10$, $\mathrm{a}=2.5$,

$$
\mathrm{b}=0.5, \mathrm{c}=1.0 \text {, right: } \mathrm{t}=10, \mathrm{a}=0.5, \mathrm{~b}=2.0, \mathrm{c}=1.5
$$

For the parameters $\alpha$ and $\beta$ in (3.3), we use the standard formula for geometric Brownian motion:

$$
\log X_{t+\Delta t}-\log X_{t}=\left(\alpha-\frac{1}{2} \sigma^{2}\right) \Delta N_{t}+\beta^{2} \Delta N_{t}
$$

As for simulation, we use Algorithm 2 in Ogata[12] and we reproduce it for the record. By assuming that the minimum value of the intensity function is $\mu$, the jump size at each point is not larger than $B$, and the $\Lambda_{i}$ are values, of the piecewise constant function such that $\lambda\left(t \mid t_{1}, \cdots, t_{n}\right) \leq \Lambda_{i}$ for $t_{n} \leq s_{i} \leq t<$ $s_{i+1} \leq t_{n+1}$.

1) Set $\Lambda_{0}=\mu$ and $s_{0}=0$.

2) Generate a random variable $U_{0}$ uniform in $(0,1)$ and put $u_{0}=-\log \left(U_{0} / \Lambda_{0}\right)$.

3) If $u_{0} \leq T$, then put $t_{1}=u_{0}$. Otherwise stop.

4) Set $i=j=k=0$ and $n=1$.

5) Set $k$ equal to $k+1$ and put $\Lambda_{k}=\lambda\left(t_{n} \mid t_{1}, \ldots, t_{n-1}\right)+B$.

6) Set $j$ equal to $j+1$ and generate $U_{j}$.

7) Set $i$ equal to $i+1$ and put $u_{i}=-\log \left(U_{j} / \Lambda_{k}\right)$.

8) Put $s_{i}=s_{i-1}+u_{i}$. If $s_{i}>T$, stop. 
9) Set $j=j+1$ and generate $U_{j}$.

10) If $U_{j} \leq \lambda\left(s_{i} \mid t_{1}, \cdots, t_{n-1}\right) / \Lambda_{k}$, set $n$ equal to $n+1$, put $t_{n}=s_{i}$ and go to step 5 . Otherwise go on.

11) Set $k$ equal to $k+1$, put $\Lambda_{k}=\lambda\left(t_{n} \mid t_{1}, \ldots, t_{n-1}\right)$ and go to step 6 .

Just as a preliminary test, we use the samples of one month data June $2012 \sim$ July 2012 and estimate the parameters $a, b$ and $c$. (See Table 2.) Note that when feeding data into (3.4), we assume that quotes in one day are uniformly distributed within the day. By using the estimates, we simulate quote numbers and compare a sample path of $N_{t}$ with the actual quotes. See Figure 6 . The result is encouraging and we proceed with some full-fledged estimations in the next subsection.

Table 2: Parameter Estimation for the Preliminary Testing

\begin{tabular}{ccccccc}
\hline & & \multicolumn{2}{c}{ Quotes } & \multicolumn{3}{c}{ Bid-Ask Spread } \\
& log-likelihood & $\hat{a}$ & $\hat{b}$ & $\hat{c}$ & $\hat{\alpha}$ & $\hat{\beta}$ \\
\hline \hline Toyota Motor & 722.229 & 5.706171 & 1.506171 & 2.13881 & -0.0004221298 & 0.005755804 \\
MetLife & 3165.603 & 6.230013 & 2.830023 & 3.191574 & 0.0006556054 & 0.0034706
\end{tabular}

\subsection{Prediction}

Let us move on to predictions of BAS via the Hawkes model. We shall conduct two types of performance tests.

\subsubsection{First Test}

We take 5 year CDS contracts and prepare three sets of in-sample period (two-and-half years) of Quotes and BAS:

(a) January 2008 to June 2010

(b) January 2009 to June 2011

(c) January 2010 to June 2012

with the respective out-of-sample period (with the length of one month) July 2010, July 2011, and July 2012. The first two periods (a) and (b) include the financial crisis within their range. By using these in-sample period data, we estimate the model parameters in (3.1) and (3.3). Then we conduct Monte 

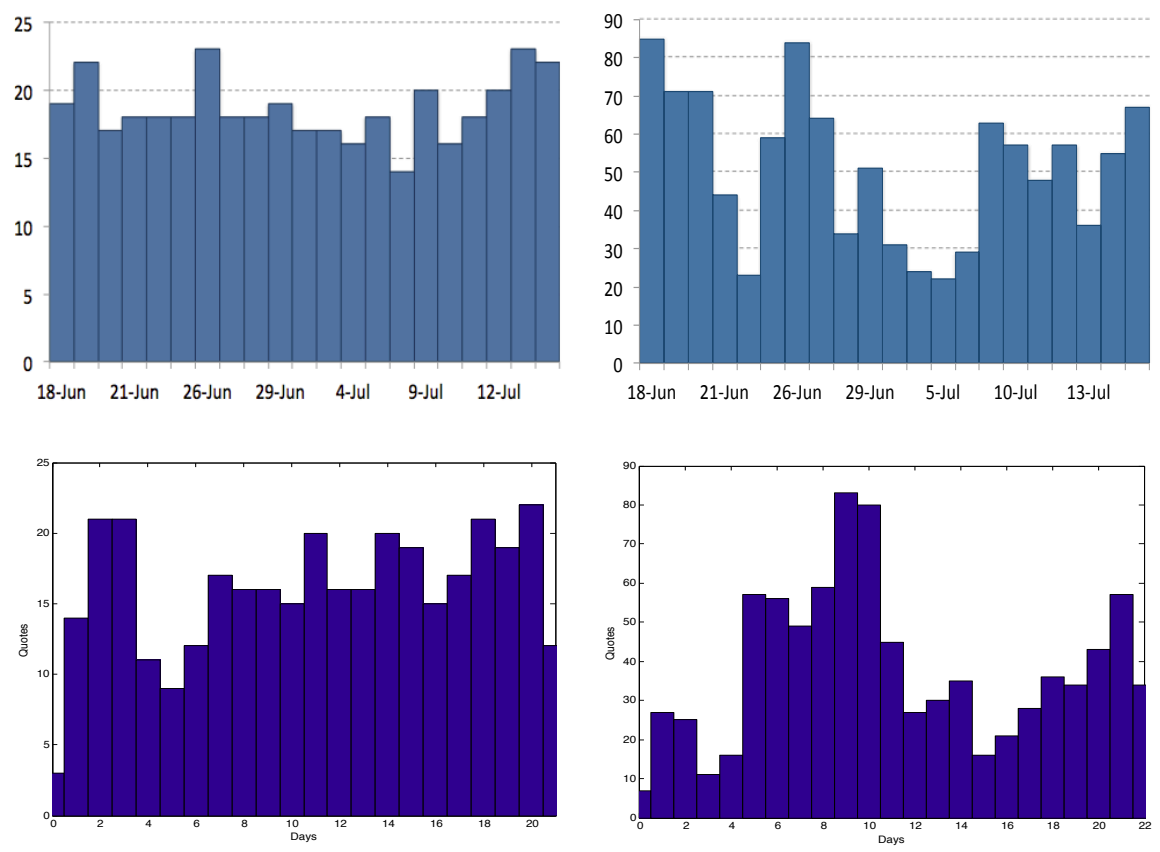

Figure 6: Comparison of observed (top) and simulated (bottom) quote numbers Left: Toyota Motor, right: MetLife

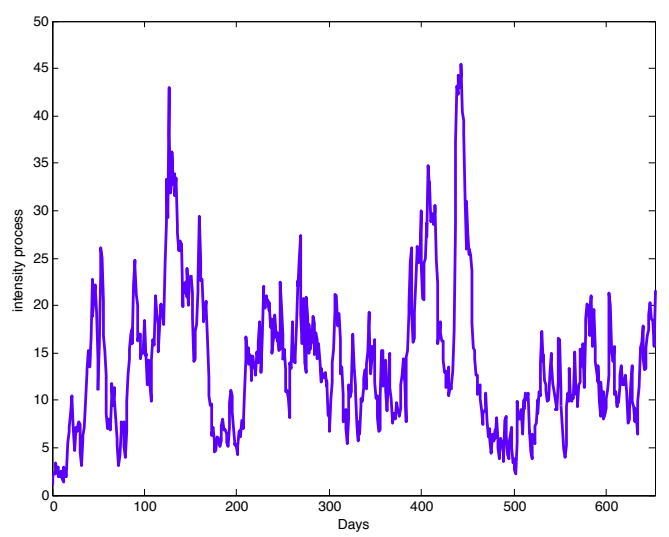

Figure 7: Intensity simulation $\mathrm{T}=650, \mathrm{a}=1.105, \mathrm{~b}=0.7034, \mathrm{c}=0.7504$ 
Carlo simulations to predict the BAS's for the out-of-sample period (for the next one month), which are compared with the actual data.

In this experiment, note that we have to take into account the following fact: If we use the Quote data of Toyota from Jan 2010 to June 2012 (two and half years), the parameters in (3.1) are estimated as $(\hat{a}, \hat{b}, \hat{c})=(1.105,0.7034,0.7504)$. A typical sample path of the Monte Carlo simulations of the intensity process is shown in Figure 7. It starts with $\hat{a}=\lambda_{0}=1.105$, but $\left(\lambda_{t}\right)_{t>0}$ spends throughout the period above the level 1.105 and at this end of this period (two and half years), $\lambda_{T}$ is above 20. Hence it is by no means appropriate to use $\hat{a}=1.105$ as the initial level of $\lambda$ for the out-of-sample period that follows. In view of this, we did the following two-step estimation:

(1) Use the whole two-and-half year sample data to estimate $(\hat{a}, \hat{b}, \hat{c})$.

(2) Use only the final one month period, re-estimate $a$, while fixing $(\hat{b}, \hat{c})$ at the values in step (1). The result is, say, $\left(\hat{a^{\prime}}, \hat{b}, \hat{c}\right)$.

(3) Simulate $(N=10,000)$, with $\left(\hat{a^{\prime}}, \hat{b}, \hat{c}\right)$, the intensity $\left(\lambda_{t}\right)_{t>0}$ for a one-month period.

This procedure is justified also by our observation that the values of $(b, c)$ are not so much varying within the two-and-half year periods. These parameters are rather characteristic of CDS reference (=company) names. The results are shown in Table 7. The reference names are Dell, AT\&T, AK Steel, Belo, Valero from the U.S. market and Toyota, Sumitomo, Softbank, Acom, and Kintetsu from Japan. We compare the actual data and simulated data in Table 8. The first (without counting the column where we put company names) column shows the observed average number of daily Quotes. The second column is the $95 \%$ confidence interval of the simulated mean. The third column is the observed average BAS in the respective one-month period, and the fourth column is the $95 \%$ confidence interval of the mean of simulated daily BAS's. The confidence intervals obtained by the Hawkes model for BAS are very narrow and generally well capture the observed BAS average within their ranges. In the periods (b) and (c), it is very rare that the estimated intervals differ from the observed spreads by more than 3 basis points. The exceptions are AK Steel and Kintetsu in period (c). Considering the facts that the period (b) contains the financial crisis in its range and the names contain both high and low credit ratings, the Hawkes model consistently well performs. Turning to the period (a), we see that the model is good in the U.S. market. But in this period, the model fails to capture the BAS for low credit names in the Japanese market (Softbank, Acom, and Kintetsu). Based on the regression results in Section 1.1, this is due to the underdeveloped state of the CDS market in Japan, especially low transaction volumes in lower credit contracts. The sixth column is the standard deviations of the observed BAS's during the 

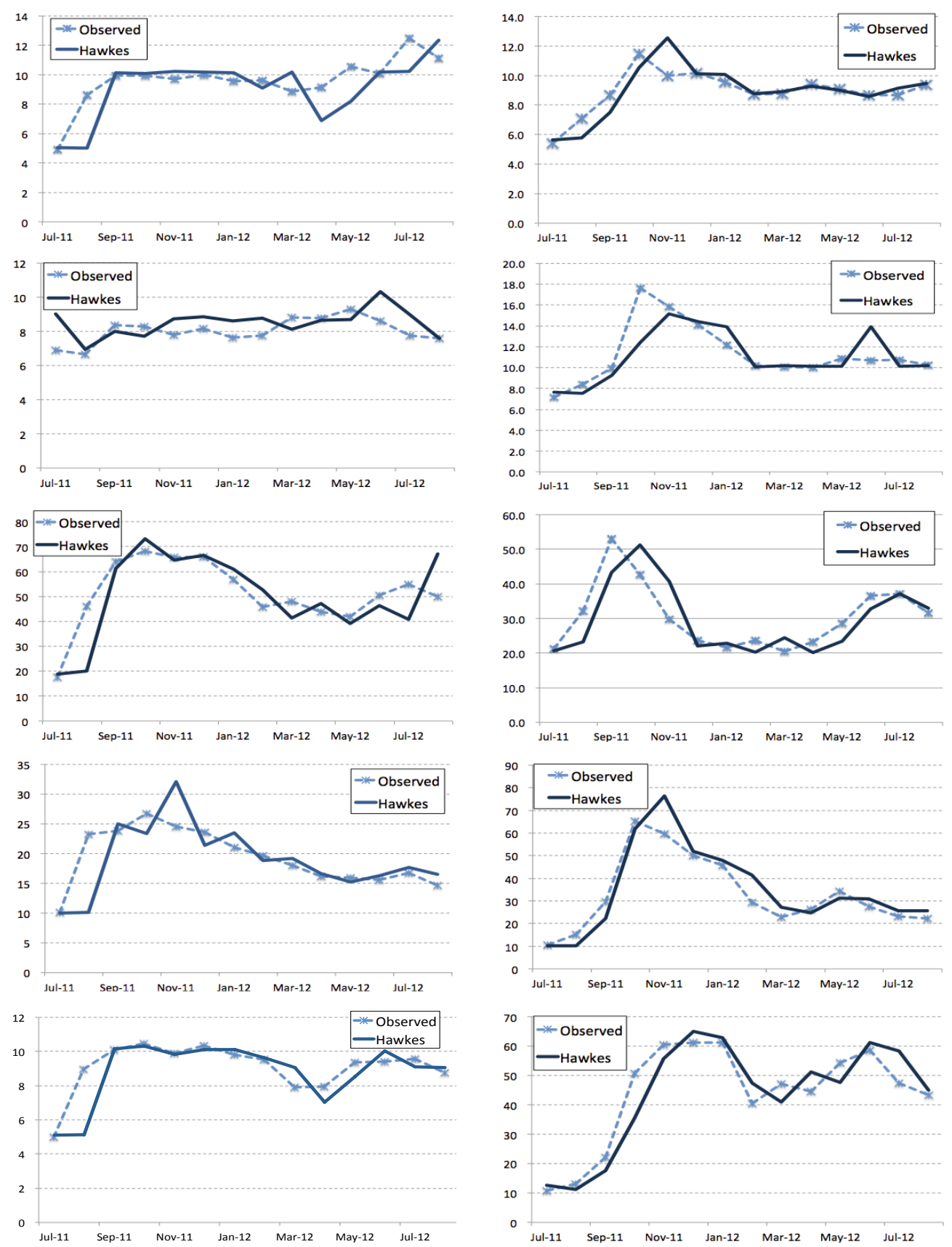

Figure 8: Comparison of 14 month bid-ask spreads (actual vs predicted)

Left: U.S.(from the top, Dell, AT\&T, AK STEEL, BELO, VALERO), Right: Japan(from the top, TOYOTA, SUMITOMO, ACOM, SOFTBANK, KINTETSU) 
one month (out-of-sample) periods. For the seventh column, we compute standard deviations of each predicted sample path of BAS's and take the average over $N=10,000$ simulations. The left end values of the confidence intervals are in general greater than the observed standard deviations. The fifth and eight columns show the $95 \%$ confidence interval obtained from ARMA-GARCH $(1,1)$. As is clearly seen, these values are by far worse than the results from the Hawkes process.

\subsubsection{Second Test:}

Again, we take 5 year CDS contracts. The next prediction experiment is done in the following way:

(a) Take fourteen sets of two-and-half year in-sample periods; (1) Jan $2009 \sim$ June 2011, (2) Feb 2009 $\sim$ July 2011, $\cdots$, and (14) Feb $2010 \sim$ July 2012, so that each adjacent set is lagged by one month.

(b) For each set, we estimate the model parameters and use these values to predict the out-of-sample periods; (1) July 2011, (2) August 2011, ․, and (14) August 2012, respectively.

(c) These predicted BAS are compared with the actual data for the fourteen months from July 2011 to August 2012. We did this procedure to the same ten companies as in the First Test.

We plot the BAS numbers (actual vs. predicted) in Figure 8. For the full results, see Tables 9 and 10 that show the estimated parameters for the two countries, and Tables 11 through 15 include actual and predicted Quotes and BAS numbers. Of course not perfect, the simulated prediction fits the actual observation pretty well. At least, the up and down trends are nicely tracked in all of the cases: both fairly stable BAS's and volatile ones. From what we observe, the Hawkes process-based prediction performs well even though there are difference between the U.S. and Japanese markets, and between higher and lower rating grade companies.

\section{Conclusion}

We have done static and dynamic analysis for both the U.S and Japanese CDS markets focusing on the bid-ask spreads. We indicate similarities and differences between the two markets and also between the high credit and low credit ratings in the above sections. In particular, in the dynamic part, we treat both long run (i.e., DCC GARCH) and short run analysis (i.e., the Hawkes process fitting). The Hawkes process based model for bid-ask spreads fits the data well. We believe that this model can be a useful tool for liquidity risk management as well. Investors with a large portfolio of credit risk exposures may 
be able to estimate transaction costs and, more importantly, foresee possible surge of bid-ask spreads ahead of time. The latter could lead to a significant amount of cost savings.

In doing prediction, one could use the most recent actual values available in the market for $a$ in (3.1), instead of using the estimated values $\hat{a}^{\prime}$ we did above. This parameter is very important because the initial level of the intensity process $\lambda$, and may improve the accuracy of predictions.

\section{A Tables}


Table 3: Adjusted $R^{2}$ in Regression and partial F-test

\begin{tabular}{|c|c|c|c|c|c|c|c|}
\hline & \multirow{2}{*}{$\begin{array}{c}\text { Rating } \\
\text { S\& P }\end{array}$} & \multicolumn{2}{|c|}{ Regres. (1.1) } & \multicolumn{2}{|c|}{ Regres. (1.2) } & \multicolumn{2}{|c|}{ F-statistics } \\
\hline & & one-year & five-year & one-year & five-year & one-year & five-year \\
\hline GENERAL ELECTRIC & $\mathrm{AA}+$ & -0.0041 & -0.0141 & 0.4837 & 0.4309 & 0.8926 & 0.4893 \\
\hline WALMART STORES & AA & 0.0736 & 0.1378 & 0.0614 & -0.0057 & 1.264 & 1.067 \\
\hline BOEING & A & 0.0828 & 0.1583 & 0.0359 & 0.0610 & 1.450 & 0.5942 \\
\hline McDONALDS & A & 0.0236 & 0.1283 & 0.0808 & -0.00631 & 0.8800 & 1.205 \\
\hline METLIFE & A- & 0.4153 & 0.4813 & 0.2875 & 0.4852 & $2.633^{*}$ & $4.740^{* *}$ \\
\hline DELL & A- & 0.0050 & 0.1734 & -0.0056 & -0.0055 & $3.504^{* *}$ & $2.201^{*}$ \\
\hline $\mathrm{AT} \& \mathrm{~T}$ & A- & 0.0347 & 0.0202 & 0.0040 & 0.3993 & 1.112 & $4.301 * *$ \\
\hline AMERICAN ELECTRIC POWER & $\mathrm{BBB}$ & 0.0493 & 0.0096 & -0.0056 & 0.012 & 1.014 & 1.108 \\
\hline VALERO ENERGY CORP & $\mathrm{BBB}$ & 0.1416 & 0.0656 & -0.0047 & -0.0060 & 0.7455 & 0.9623 \\
\hline DOW CHEMICAL & $\mathrm{BBB}$ & 0.2116 & 0.2845 & 0.0891 & 0.0219 & 0.8108 & 1.3201 \\
\hline average in Investment Grade & & 0.1033 & 0.1532 & 0.1026 & 0.1387 & & \\
\hline INTERNATIONAL LEASE FINANCE & BBB- & 0.2448 & 0.3183 & 0.0413 & 0.2742 & $5.071^{* *}$ & $13.67 * *$ \\
\hline FORD MOTOR & $\mathrm{BB}+$ & 0.1717 & 0.1956 & 0.2289 & 0.5616 & 1.036 & $3.213^{* *}$ \\
\hline AK STEEL & $\mathrm{BB}-$ & 0.0374 & 0.1900 & 0.0280 & 0.0065 & 0.5910 & 0.8333 \\
\hline BELO CORP & BB- & 0.0249 & 0.0848 & 0.0244 & 0.1496 & $5.092 * *$ & 1.514 \\
\hline FOREST OIL & BB- & 0.1009 & 0.2579 & 0.0459 & 0.1017 & $2.2331^{*}$ & $2.414^{*}$ \\
\hline UNISYS & BB- & 0.2013 & 0.2590 & -0.0055 & 0.1197 & $8.763^{* *}$ & $17.30^{* *}$ \\
\hline IRON MOUNTAIN & BB- & 0.0526 & 0.0446 & -0.0044 & 0.0728 & 1.960 & 1.559 \\
\hline CHESAPEAKE ENERGY & BB- & 0.0750 & 0.2905 & -0.0001 & 0.0892 & $2.548^{*}$ & $7.405 * *$ \\
\hline ALLY FINANCIAL & $\mathrm{B}+$ & 0.6291 & 0.6121 & 0.1810 & 0.2054 & $4.611^{* *}$ & $9.877 * *$ \\
\hline MGIC INVESTMENT & $\mathrm{CCC}+$ & 0.0452 & 0.1906 & 0.0389 & 0.2472 & $14.63^{* *}$ & 1.830 \\
\hline average in High Yield & & 0.1583 & 0.2443 & 0.0578 & 0.1887 & & \\
\hline \multirow[t]{3}{*}{ average in U.S. } & & 0.1308 & 0.1988 & 0.0802 & 0.1637 & & \\
\hline & Rating & \multicolumn{2}{|c|}{ Regres. (1.1) } & \multicolumn{2}{|c|}{ Regres. (1.2) } & \multicolumn{2}{|c|}{ F-statistics } \\
\hline & $\mathrm{R} \& \mathrm{I}$ & one-year & five-year & one-year & five-year & one-year & five-year \\
\hline TOYOTA MOTOR & AAA & 0.0184 & 0.0586 & 0.0114 & 0.0067 & 1.120 & 1.844 \\
\hline CHUBU ELECTRIC POWER & AA & 0.0044 & -0.0030 & -0.0028 & 0.0291 & 0.9378 & $2.163^{*}$ \\
\hline NIPPON STEEL & AA & 0.0689 & 0.1650 & -0.0031 & -0.0047 & 0.7972 & 0.8567 \\
\hline ASAHI GROUP & AA- & -0.0001 & 0.0037 & -0.0031 & -0.0047 & 0.5756 & 0.3447 \\
\hline NOMURA HOLDINGS & AA- & -0.0050 & -0.0133 & 0.0033 & -0.0059 & 0.9868 & 1.311 \\
\hline SUMITOMO CORP & AA- & 0.0127 & 0.0142 & 0.0466 & 0.0687 & $3.412^{* *}$ & $3.670^{* *}$ \\
\hline HITACHI & AA- & 0.0524 & 0.1647 & 0.0735 & 0.1605 & 1.807 & $2.367^{*}$ \\
\hline SOFTBANK & A & -0.0046 & 0.0071 & -0.0014 & 0.1164 & $2.862^{* *}$ & 2.022 \\
\hline $\mathrm{ACOM}$ & A & 0.0850 & 0.1114 & 0.0263 & 0.0157 & 1.394 & 1.574 \\
\hline AEON & A & 0.0152 & 0.0420 & 0.0179 & 0.088 & $2.324^{*}$ & $3.942^{* *}$ \\
\hline average in investmant grade & & 0.0247 & 0.0550 & 0.0188 & 0.047 & & \\
\hline MAZDA MOTOR & $\mathrm{BBB}+$ & -0.0039 & -0.0129 & 0.1507 & 0.1403 & 1.266 & 1.658 \\
\hline MITSUBISHI MATERIALS & $\mathrm{BBB}+$ & -0.0125 & -0.0036 & 0.0959 & -0.0062 & 1.298 & 1.061 \\
\hline KINTETSU & $\mathrm{BBB}+$ & 0.0494 & 0.0876 & 0.1153 & 0.0103 & 0.6445 & 0.3521 \\
\hline SAPPORO HOLDINGS & $\mathrm{BBB}+$ & -0.0128 & -0.0097 & 0.2300 & 0.3034 & 2.100 & 1.012 \\
\hline IHI & $\mathrm{BBB}+$ & -0.0133 & -0.0155 & -0.0049 & 0.0208 & 1.387 & 1.873 \\
\hline MAEDA & $\mathrm{BBB}+$ & -0.0248 & 0.0117 & -0.0067 & 0.1166 & 0.3202 & 0.3023 \\
\hline ANRITSU & $\mathrm{BBB}+$ & 0.0271 & -0.0324 & 0.9485 & 0.7406 & $3.127^{* *}$ & 1.524 \\
\hline SHINSEI BANK & ВBB & 0.0002 & -0.0013 & 0.2537 & 0.0467 & 0.6448 & 0.6355 \\
\hline PIONEER & $\mathrm{BBB}$ & 0.051 & 0.2000 & -0.0049 & 0.0208 & 0.4197 & 1.479 \\
\hline AIFUL & $\mathrm{CCC}$ & 0.0112 & 0.0189 & 0.1708 & 0.3488 & 0.5414 & 0.5314 \\
\hline average in High Yield & & 0.0018 & 0.0243 & 0.1741 & 0.1716 & & \\
\hline average in Japan & & 0.0132 & 0.0397 & 0.0965 & 0.1093 & & \\
\hline
\end{tabular}

p-value less than ${ }^{* *}: 1$ percent, ${ }^{*}: 5$ percent 
Table 4: Coefficients to regress Bid-Ask Spreads in one-year contract CDS

\begin{tabular}{|c|c|c|c|c|c|c|c|c|}
\hline & $\Delta(\mathrm{Bid})$ & $\Delta$ (Interest) & $\Delta(\mathrm{VI})$ & $\Delta$ (Volume $)$ & $\Delta($ StockPrice $)$ & $\Delta($ StockSigma $)$ & $\Delta($ StockVol $)$ & $\Delta$ (Crisis) \\
\hline $\mathrm{GE}$ & $0.2907^{* *}$ & 1.4353 & -0.0523 & -1.2417 & 10.1862 & 11.9972 & 1.1781 & \\
\hline WALMART & $-0.2075^{* *}$ & 0.3970 & $0.1183^{*}$ & 0.7001 & 5.7987 & -74.0718 & 0.5392 & -0.0041 \\
\hline BOEING & $0.0945^{* *}$ & 0.4920 & -0.0594 & -0.6176 & 15.8032 & 50.7611 & -0.8783 & 0.0916 \\
\hline MCDONALDS & $-0.2545^{* *}$ & -1.2862 & 0.0246 & -1.0882 & -7.9366 & 0.1341 & 0.8426 & 0.0544 \\
\hline METLIFE & $0.2064^{* *}$ & -6.5181 & -0.1835 & -6.4302 & 118.0829 & 191.4951 & 9.9764 & 0.5749 \\
\hline DELL & 0.0225 & -0.3574 & $-0.1762^{* *}$ & 0.4616 & $-24.7058^{*}$ & $-86.5426^{* *}$ & $3.3039^{* *}$ & -0.0636 \\
\hline AT\& $\mathrm{T}$ & $-0.0667^{*}$ & 0.2654 & 0.0742 & 0.5945 & 19.1169 & 8.7033 & 1.8140 & 0.0819 \\
\hline AMERICAN ELEC & 0.0058 & -1.4441 & -0.0414 & -0.4360 & -4.9118 & 41.7283 & 0.0246 & 0.0354 \\
\hline VALERO & -0.0025 & -2.3010 & -0.0199 & -0.2877 & 16.0494 & 1.7587 & 0.7588 & 0.1094 \\
\hline DOW CHEM & $0.0709^{* *}$ & -2.2646 & -0.0547 & -0.0598 & 8.6793 & 28.0496 & 1.6709 & 0.0262 \\
\hline FORD & $0.1271^{* * *}$ & 60.4911 & -0.4105 & -9.4144 & -182.8653 & 111.2600 & 16.0730 & 0.8918 \\
\hline AK STEEL & $0.0659^{* *}$ & 3.9242 & 0.0223 & -4.1301 & -44.3807 & -111.5615 & 3.1360 & -0.5274 \\
\hline BELO & $0.0571^{* *}$ & 6.5147 & $2.0444^{* *}$ & 17.6603 & -93.0524 & $-373.1725^{* *}$ & -14.3063 & 0.6033 \\
\hline FOREST OIL & $0.0949^{* *}$ & -12.7739 & $-0.8435^{* *}$ & -2.2583 & -36.3112 & -105.9673 & 0.5321 & -0.0171 \\
\hline UNISYS & $-0.0575^{*}$ & 53.3839 & $-5.9294^{*}$ & $121.096^{*}$ & $-648.0591^{* *}$ & $2431.2284^{* *}$ & $-153.4435^{* *}$ & 0.70194 \\
\hline IRON MOUNT & -0.000765 & $-5.2244^{*}$ & 0.1296 & 2.6758 & -1.3485 & 7.3423 & -1.2660 & -0.1488 \\
\hline CHESAPEAKE & 0.0874 & -13.5363 & $-2.4360^{* *}$ & 18.6688 & 34.2353 & 292.7386 & 5.8817 & 0.2696 \\
\hline ALLY FIN & $0.121^{* *}$ & 55.520 & 0.277 & 65.886 & 249.358 & $1424.196^{* *}$ & 10.371 & -1.233 \\
\hline INTER LEASE & 0.0431 & -45.2685 & -1.3462 & 8.5344 & $-200.9290^{* *}$ & $258.4313^{*}$ & -9.8886 & -1.7914 \\
\hline \multirow[t]{2}{*}{ MGIC } & $-0.1772^{* *}$ & 0.3973 & -0.8202 & $-57.8877^{*}$ & $-443.8731^{* *}$ & $854.4722^{* *}$ & 1.2105 & -2.9807 \\
\hline & $\Delta(\mathrm{Bid})$ & $\Delta$ (Interest) & $\Delta(\mathrm{VI})$ & $\Delta($ Volume $)$ & $\Delta($ StockPrice $)$ & $\Delta($ StockSigma $)$ & $\Delta($ StockVol $)$ & $\Delta($ Crisis $)$ \\
\hline TOYOTA & $0.0750^{*}$ & -1.7605 & 0.0215 & -0.6001 & $-30.2484 *$ & -19.3537 & 0.6859 & -0.1581 \\
\hline CHUBU & 0.0483 & -0.4397 & $0.0960^{*}$ & -0.6300 & 13.2446 & -34.4850 & 0.6574 & 0.1404 \\
\hline NIPPON STEEL & 0.0398 & 0.0909 & 0.1136 & -3.2692 & 5.6861 & 34.0362 & -0.2207 & -0.0197 \\
\hline ASAHI & $-0.1743^{* *}$ & 0.1162 & -3.6418 & -0.8729 & -12.7071 & -57.8543 & 0.8834 & -0.0608 \\
\hline NOMURA & 0.0535 & 1.29484 & -0.0089 & -4.9527 & $-72.4630^{*}$ & -59.0562 & -1.0178 & -0.4256 \\
\hline SUMITOMO & $0.2001^{* *}$ & -9.5908 & -0.0704 & -4.9918 & $90.6216^{* *}$ & 40.8240 & 5.0567 & -0.7049 \\
\hline HITACHI & $0.2784^{* *}$ & -7.6758 & 0.1962 & 2.9388 & 24.4244 & 61.2449 & $-5.4337^{*}$ & 0.0014 \\
\hline SOFTBANK & 0.0653 & 27.1565 & -0.4313 & $-69.9410 * *$ & -30.2923 & -26.3252 & -10.9522 & -0.7359 \\
\hline $\mathrm{ACOM}$ & $-0.2270^{*}$ & 0.8249 & 1.6660 & 63.1870 & 20.3758 & 342.1862 & -39.6392 & -0.4889 \\
\hline AEON & $-0.1710^{* *}$ & 22.1799 & -0.4404 & -2.9913 & $-154.3648^{* *}$ & -230.6126 & 9.9578 & -0.0267 \\
\hline MAZDA & $0.3077^{* *}$ & 6.9161 & -0.4788 & 8.3572 & 1.0218 & -7.8888 & 3.7957 & -0.0118 \\
\hline MATERIALS & $-0.2066^{* *}$ & -2.4028 & 0.1223 & 1.7258 & -15.3096 & -67.9243 & 1.6973 & 1.1109 \\
\hline KINTETSU & $-0.3615^{* *}$ & -12.0857 & 0.0533 & -8.5618 & -7.2398 & -121.4281 & 4.1523 & -0.2595 \\
\hline SAPPORO & $0.4274^{* *}$ & 6.7441 & -0.5101 & -7.5348 & $-117.4324^{*}$ & 255.8141 & -0.5101 & \\
\hline IHI & -0.0030 & -17.8202 & -0.5927 & $-48.1890^{*}$ & 6.6656 & 180.2065 & 22.9154 & -0.3996 \\
\hline MAEDA & -0.0281 & -10.6764 & -0.0324 & 2.7386 & -2.0083 & -47.6794 & -0.9447 & \\
\hline ANRITSU & $0.1504^{* *}$ & -0.0388 & 0.0004 & 0.0574 & -0.1979 & $-1.9310^{* *}$ & -0.0332 & \\
\hline SHINSEI & $-0.4533^{* *}$ & -9.1703 & -1.2079 & 5.0721 & -226.8239 & -79.9928 & -13.5235 & -4.1858 \\
\hline PIONEER & 0.0119 & -0.5142 & 0.0710 & -6.1342 & 0.0738 & -6.0303 & 1.8319 & 0.0658 \\
\hline AIFUL & $0.1181^{* *}$ & 94.4605 & 4.6687 & -178.1841 & 309.5854 & 505.0846 & 41.0710 & 19.0328 \\
\hline
\end{tabular}

p-value less than ${ }^{* *}: 1$ percent, $*: 5$ percent 
Table 5: Coefficients of VAR and F statistics in the Granger causality test

\begin{tabular}{|c|c|c|c|c|c|c|}
\hline & \multicolumn{2}{|c|}{$b_{21}$} & \multicolumn{2}{|c|}{$b_{22}$} & \multicolumn{2}{|c|}{$\Delta(B A S)_{t-1} \rightarrow \Delta(B i d)_{t}$} \\
\hline & one-year & five-year & one-year & five-year & one-year & five-year \\
\hline GE & 0.1112 & 0.0013 & -0.6327 & -0.3711 & $3.9086^{*}$ & 0.0281 \\
\hline WALMART & 0.1027 & 0.0420 & -0.3586 & -0.4183 & $6.5872^{*}$ & 0.0284 \\
\hline BOEING & 0.0973 & 0.0393 & -0.4157 & -0.3270 & 0.0443 & 1.6247 \\
\hline MCDONALDS & 0.0821 & 0.0122 & -0.2437 & -0.5034 & $4.3776^{*}$ & 0.0505 \\
\hline METLIFE & 0.1359 & 0.0077 & -0.2222 & -0.1810 & 0.6520 & 0.0021 \\
\hline DELL & 0.1844 & 0.05668 & -0.2214 & -0.3842 & $13.2521^{* *}$ & $13.2715^{* *}$ \\
\hline AT\& T & 0.1388 & -0.1948 & -0.3243 & -0.5985 & 2.3919 & $79.4863^{* *}$ \\
\hline AMERICAN ELEC & 0.0481 & 0.02366 & -0.4518 & -0.4895 & 2.5624 & 1.5244 \\
\hline VALERO & 0.0266 & 0.0072 & -0.4184 & -0.4929 & $6.8563^{* *}$ & 0.9108 \\
\hline DOW CHEM & 0.0261 & 0.0152 & -0.5347 & -0.4633 & 2.7214 & 0.0932 \\
\hline FORD & -0.0348 & 0.0424 & -0.2581 & -0.4149 & $46.7527^{* *}$ & 2.2168 \\
\hline AK STEEL & 0.0375 & 0.0194 & -0.4400 & -0.5855 & 0.6098 & 0.0654 \\
\hline BELO CORP & 0.0997 & 0.0241 & -0.3302 & -0.0891 & $32.7864^{* *}$ & $4.4147^{*}$ \\
\hline FOREST OIL & 0.0063 & 0.0243 & -0.3302 & -0.3853 & $8.7364^{* *}$ & 0.2129 \\
\hline UNISYS & 0.0342 & 0.0242 & -0.2074 & -0.0296 & $10.3175^{* *}$ & 2.162 \\
\hline IRON MOUNT & -0.0336 & -0.0111 & -0.3493 & -0.5323 & 1.1223 & $6.7821^{* *}$ \\
\hline CHESAPEAKE & 0.2038 & 0.0645 & -0.4258 & -0.3973 & $5.3495^{*}$ & 0.0777 \\
\hline ALLY FIN & 0.0907 & 0.2201 & -0.2989 & -0.6264 & $24.0233^{* *}$ & 0.695 \\
\hline INTER LEASE & 0.0221 & 0.0112 & -0.4850 & -0.4874 & 1.5611 & $6.3805^{*}$ \\
\hline \multirow[t]{3}{*}{ MGIC } & -0.0077 & 0.0320 & -0.3865 & -0.4915 & 1.6269 & $13.1742^{* *}$ \\
\hline & \multicolumn{2}{|c|}{$b_{21}$} & \multicolumn{2}{|c|}{$b_{22}$} & \multicolumn{2}{|c|}{$\Delta(B A S)_{t-1} \rightarrow \Delta(B i d)_{t}$} \\
\hline & one-year & five-year & one-year & five-year & one-year & five-year \\
\hline TOYOTA & 0.2656 & 0.0985 & -0.3140 & -0.3607 & $13.2953^{* *}$ & $8.0016^{* *}$ \\
\hline CHUBU ELEC & -0.0087 & 0.0519 & -0.0764 & -0.1593 & $3.8622^{*}$ & 1.3519 \\
\hline NIPPON STEEL & 0.2916 & 0.1413 & -0.3812 & -0.3846 & 0.094 & 2.1191 \\
\hline ASAHI & 0.2981 & 0.0983 & -0.1464 & -0.2458 & $20.413^{* *}$ & $12.8373^{* *}$ \\
\hline NOMURA & 0.0013 & 0.0013 & -0.2645 & -0.3155 & 0.6699 & 0.4889 \\
\hline SUMITOMO & 0.1218 & 0.0668 & -0.3071 & -0.3627 & 0.0183 & $3.9927^{*}$ \\
\hline HITACHI & 0.2713 & 0.1992 & -0.3545 & -0.3038 & 1.9351 & $11.9009^{* *}$ \\
\hline SOFTBANK & 0.1122 & 0.1495 & -0.4015 & -0.4195 & 2.6972 & 0.5928 \\
\hline $\mathrm{ACOM}$ & 0.0253 & 0.0164 & -0.3948 & -0.3982 & $34.4122^{* *}$ & $5.4584^{*}$ \\
\hline AEON & 0.2897 & 0.0972 & -0.1583 & -0.2863 & $55.3525^{* *}$ & $43.4629^{* *}$ \\
\hline MAZDA & 0.0519 & 0.0293 & -0.1650 & -0.1877 & $17.302^{* *}$ & $6.8298^{* *}$ \\
\hline MATERIALS & 0.1888 & 0.0338 & -0.3032 & -0.3713 & $7.2391^{* *}$ & 0.0021 \\
\hline KINTETSU & 0.3480 & 0.2253 & -0.3133 & -0.3750 & $7.0442^{* *}$ & 0.0974 \\
\hline SAPPORO & -0.0815 & -0.0057 & 0.1466 & -0.0046 & $13.1345^{* *}$ & $23.5656^{* *}$ \\
\hline SHINSEI & 0.00327 & 0.0238 & -0.0980 & -0.1220 & 1.5847 & 0.0025 \\
\hline PIONEER & 0.0345 & 0.0328 & -0.2008 & -0.3238 & 0.0034 & 0.3243 \\
\hline AIFUL & -0.0823 & -0.0734 & -0.1692 & -0.1296 & 2.9913 & 1.1188 \\
\hline IHI & 0.1127 & 0.0314 & -0.0173 & -0.0565 & 2.1031 & 1.1289 \\
\hline MAEDA & 0.0190 & -0.0059 & -0.0120 & -0.0586 & 0.0032 & 3.1155 \\
\hline ANRITSU & -0.0275 & 0.0781 & -0.0063 & -0.1524 & 0 & 0.0365 \\
\hline
\end{tabular}

p-value less than ${ }^{* *} 22^{\text {percent, }}{ }^{*}: 5$ percent 
Table 6: Granger causality test between Bid and Quotes, BAS and Quotes

\begin{tabular}{|c|c|c|c|c|}
\hline & $\Delta(\text { Bid })_{t-1} \rightarrow \Delta\left(\right.$ Quotes $_{t}$ & $\Delta\left(\right.$ Quotes $_{t-1} \rightarrow \Delta(\text { Bid })_{t}$ & $\Delta(B A S)_{t-1} \rightarrow \Delta(\text { Quotes })_{t}$ & $\Delta\left(\right.$ Quotes $_{t-1} \rightarrow \Delta(B A S)_{t}$ \\
\hline GE & 0.0126 & 0.1467 & 0.488 & 0.0018 \\
\hline WALMART & 0.3211 & 0.3495 & 1.3608 & 1.6334 \\
\hline BOEING & 0.6142 & 0.5963 & 2.8584 & $4.1077^{*}$ \\
\hline MCDONALDS & 0.7744 & 0.0283 & 0.0082 & 0.4433 \\
\hline METLIFE & $9.1977^{* *}$ & 0.9902 & 1.8125 & $4.1901^{*}$ \\
\hline DELL & 0.0888 & 2.6586 & 1.1392 & $26.8677^{* *}$ \\
\hline AT\& $\mathrm{T}$ & 0.0316 & 0.0198 & 0.7673 & 0.5893 \\
\hline AMERICAN ELEC & $11.0412^{* *}$ & 0.1619 & 1.8172 & 2.1367 \\
\hline VALERO & 0.8376 & 0.0053 & $6.7073^{* *}$ & 0.3051 \\
\hline DOW CHEM & 2.2826 & 0.1150 & 0.9203 & 2.8238 \\
\hline FORD & 0.0565 & $14.2146^{* *}$ & 0.1062 & 0.0788 \\
\hline AK STEEL & 0.9162 & $3.8678^{*}$ & 0.433 & 0.3012 \\
\hline BELO CORP & 1.3848 & 0.0719 & 0.2586 & 2.0608 \\
\hline FOREST OIL & 2.2936 & 0.1359 & 1.6904 & 0.9324 \\
\hline UNISYS & 0.7487 & 0.4223 & 0.2903 & 1.3612 \\
\hline IRON MOUNT & 1.1246 & 1.3863 & $69.8123^{* *}$ & 1.8085 \\
\hline CHESAPEAKE & $9.2459 * *$ & 0.0202 & $10.7715^{* *}$ & $3.9106^{*}$ \\
\hline ALLY FIN & 0.0766 & 0.1347 & 0.0125 & 0.0495 \\
\hline ARAMARK & 0 & 0.0775 & 0.0048 & 0.4188 \\
\hline \multirow[t]{2}{*}{ SPRINGLEAF } & 0.0424 & 0.1672 & 0.0515 & 0.952 \\
\hline & $\Delta(\text { Bid })_{t-1} \rightarrow \Delta(\text { Quotes })_{t}$ & $\Delta(\text { Quotes })_{t-1} \rightarrow \Delta(\text { Bid })_{t}$ & $\Delta(B A S)_{t-1} \rightarrow \Delta(\text { Quotes })_{t}$ & $\Delta\left(\right.$ Quotes $_{t-1} \rightarrow \Delta(B A S)_{t}$ \\
\hline TOYOTA & 0.2123 & 0.9189 & 0.0206 & 0.3146 \\
\hline CHUBU ELEC & 2.1346 & 0.2582 & 0.3988 & 0.5898 \\
\hline NIPPON STEEL & 1.4048 & 0.5576 & 0.4671 & 0.1592 \\
\hline NOMURA & 0.9771 & 0.2091 & 0.2473 & 0.3415 \\
\hline SUMITOMO & 0.0004 & 0.0221 & 0 & 0.0331 \\
\hline HITACHI & 0.0805 & 0.0294 & 0.9203 & 2.4511 \\
\hline SOFTBANK & $5.578^{*}$ & 0.4172 & 0.5381 & 0.0765 \\
\hline $\mathrm{ACOM}$ & 0.7454 & 0.0847 & 0.0003 & 2.0202 \\
\hline AEON & 0.0548 & 1.7679 & 0.0663 & 0.2014 \\
\hline SHARP & 2.8663 & 1.0018 & 0.5245 & 1.5966 \\
\hline TOKELP & 0.4357 & 0.0143 & 1.1331 & 0.2273 \\
\hline MAZDA & 1.2618 & 2.8038 & 0.968 & $6.2024^{*}$ \\
\hline MATERIALS & 1.134 & 0.0593 & 1.6805 & 2.4058 \\
\hline KINTETSU & 1.3664 & 0.0197 & 0.6691 & $6.0978^{*}$ \\
\hline SAPPORO & 0.001 & 0.0076 & 0.2227 & 0.9759 \\
\hline SOJITZ & 0.0016 & 1.2445 & 0.9577 & 1.0536 \\
\hline SHINSEI & 0.0242 & 3.0059 & 0.3434 & 0.094 \\
\hline PIONEER & 1.4086 & $14.2741^{* *}$ & $34.2881 * *$ & $8.9154^{* *}$ \\
\hline AIFUL & 1.2228 & 0.0736 & 0.1074 & 0 \\
\hline
\end{tabular}

p-value less than ${ }^{* *}: 1$ percent, $*: 5$ percent 
Table 7: Estimated Parameters from the Hawkes Model July-2010 Brownian Subordination $X_{t} \quad$ Hawkes process $N_{t}$

\begin{tabular}{lcc|ccc} 
& $\alpha$ & $\beta$ & $\mathrm{a}$ & $\mathrm{b}$ & $\mathrm{c}$ \\
\hline \hline DELL & 0.00006651 & 0.01076 & 5.3136 & 1.9640 & 2.0275 \\
AT\&T & 0.0004781 & 0.02942 & 3.0525 & 0.73559 & 0.77562 \\
AK STEEL & 0.00001813 & 0.005699 & 1.9697 & 4.4200 & 4.4961 \\
BELO & 0.00001244 & 0.005040 & 4.6798 & 5.4263 & 5.4675 \\
VALERO & 0.00007151 & 0.01100 & 3.5399 & 3.1716 & 3.2918 \\
TOYOTA & 0.0002054 & 0.01954 & 4.2457 & 0.58286 & 0.62786 \\
SUMITOMO & 0.0003156 & 0.02314 & 2.4338 & 0.59184 & 0.66534 \\
SOFTBANK & 0.0007965 & 0.03557 & 1.2520 & 0.70781 & 0.74581 \\
ACOM & 0.0005500 & 0.02761 & 2.0678 & 0.57667 & 0.63167 \\
KINTETSU & 0.0007635 & 0.03358 & 2.8860 & 0.28772 & 0.30472 \\
\hline
\end{tabular}

July-2011 Brownian Subordination $X_{t} \quad$ Hawkes process $N_{t}$

\begin{tabular}{lcc|ccc} 
& $\alpha$ & $\beta$ & $\mathrm{a}$ & $\mathrm{b}$ & $\mathrm{c}$ \\
\hline \hline DELL & 0.00001504 & 0.007841 & 5.6042 & 2.3983 & 2.4643 \\
AT\&T & 0.0002281 & 0.02174 & 3.3623 & 1.0487 & 1.1244 \\
AK STEEL & 0.000004735 & 0.005419 & 4.3726 & 4.5364 & 4.6039 \\
BELO & 0.00000003761 & 0.004458 & 5.2618 & 4.8533 & 4.9274 \\
VALERO & 0.00002346 & 0.009111 & 5.2234 & 3.3609 & 3.4746 \\
TOYOTA & 0.00001659 & 0.01356 & 2.6224 & 0.74000 & 0.78350 \\
SUMITOMO & 0.00005132 & 0.01686 & 2.8330 & 0.68333 & 0.73233 \\
SOFTBANK & 0.0003955 & 0.03520 & 1.6353 & 0.59403 & 0.64523 \\
ACOM & 0.0002321 & 0.02443 & 3.1280 & 0.64436 & 0.70577 \\
KINTETSU & 0.00005990 & 0.01726 & 3.4686 & 0.50163 & 0.55862 \\
\hline
\end{tabular}

July-2012 Brownian Subordination $X_{t} \quad$ Hawkes process $N_{t}$

\begin{tabular}{lcc|ccc} 
& $\alpha$ & $\beta$ & $\mathrm{a}$ & $\mathrm{b}$ & $\mathrm{c}$ \\
\hline \hline DELL & 0.00002012 & 0.005093 & 5.8658 & 2.5437 & 2.6073 \\
AT\&T & 0.0001426 & 0.01595 & 2.5936 & 1.1945 & 1.2901 \\
AK STEEL & 0.00006131 & 0.009857 & 4.9799 & 2.1003 & 2.1417 \\
BELO & 0.00001767 & 0.006032 & 4.1613 & 2.4111 & 2.4738 \\
VALERO & 0.00001138 & 0.005074 & 7.8070 & 2.2409 & 2.4085 \\
TOYOTA & 0.00007224 & 0.01202 & 3.8004 & 0.70337 & 0.75037 \\
SUMITOMO & 0.00006464 & 0.01380 & 3.3897 & 0.69198 & 0.75398 \\
SOFTBANK & 0.0002347 & 0.02638 & 2.9605 & 0.41663 & 0.46977 \\
ACOM & 0.0001325 & 0.01707 & 2.4390 & 0.64387 & 0.72749 \\
KINTETSU & 0.0001388 & 0.01364 & 3.9440 & 0.55844 & 0.62944
\end{tabular}



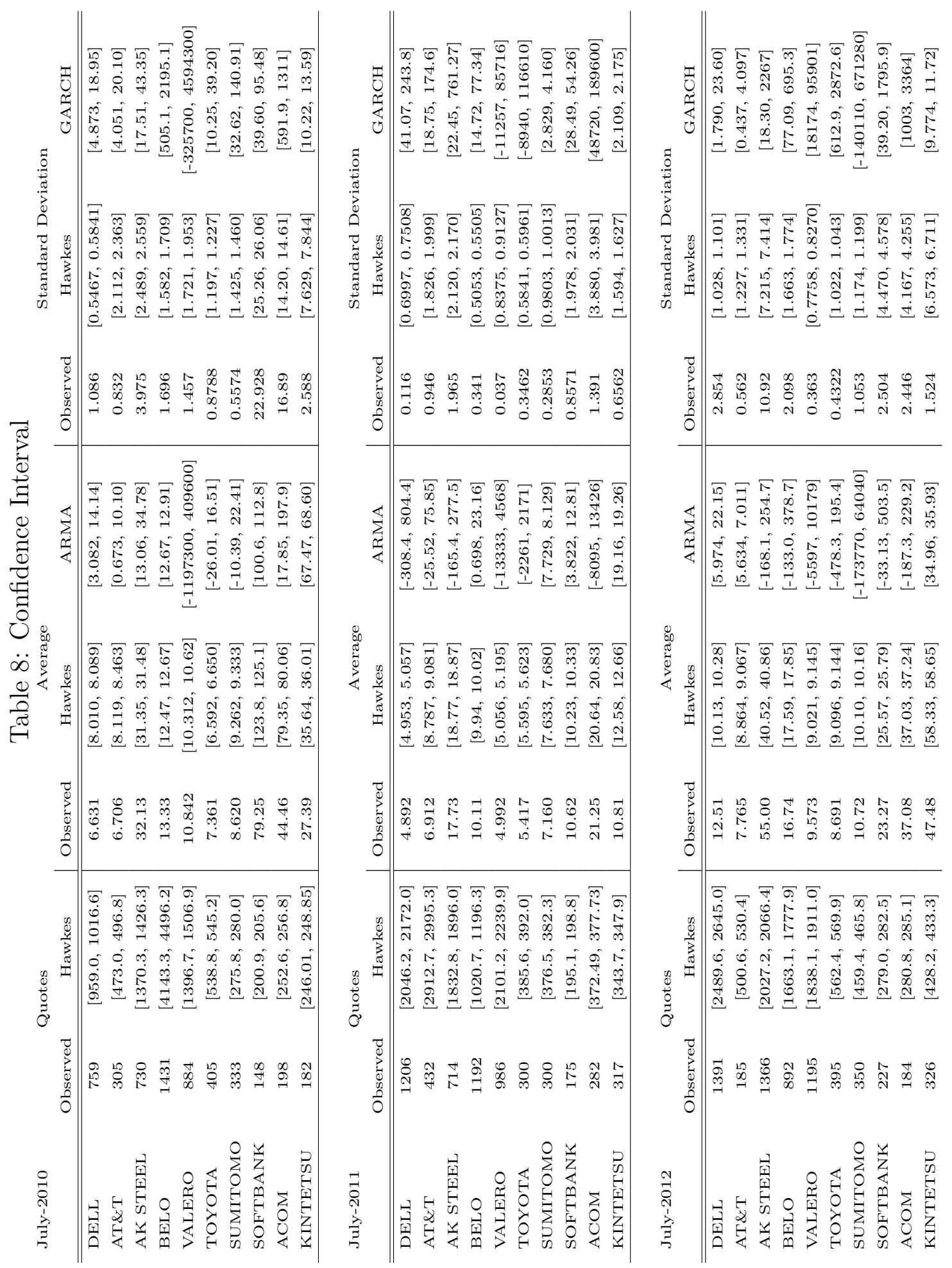


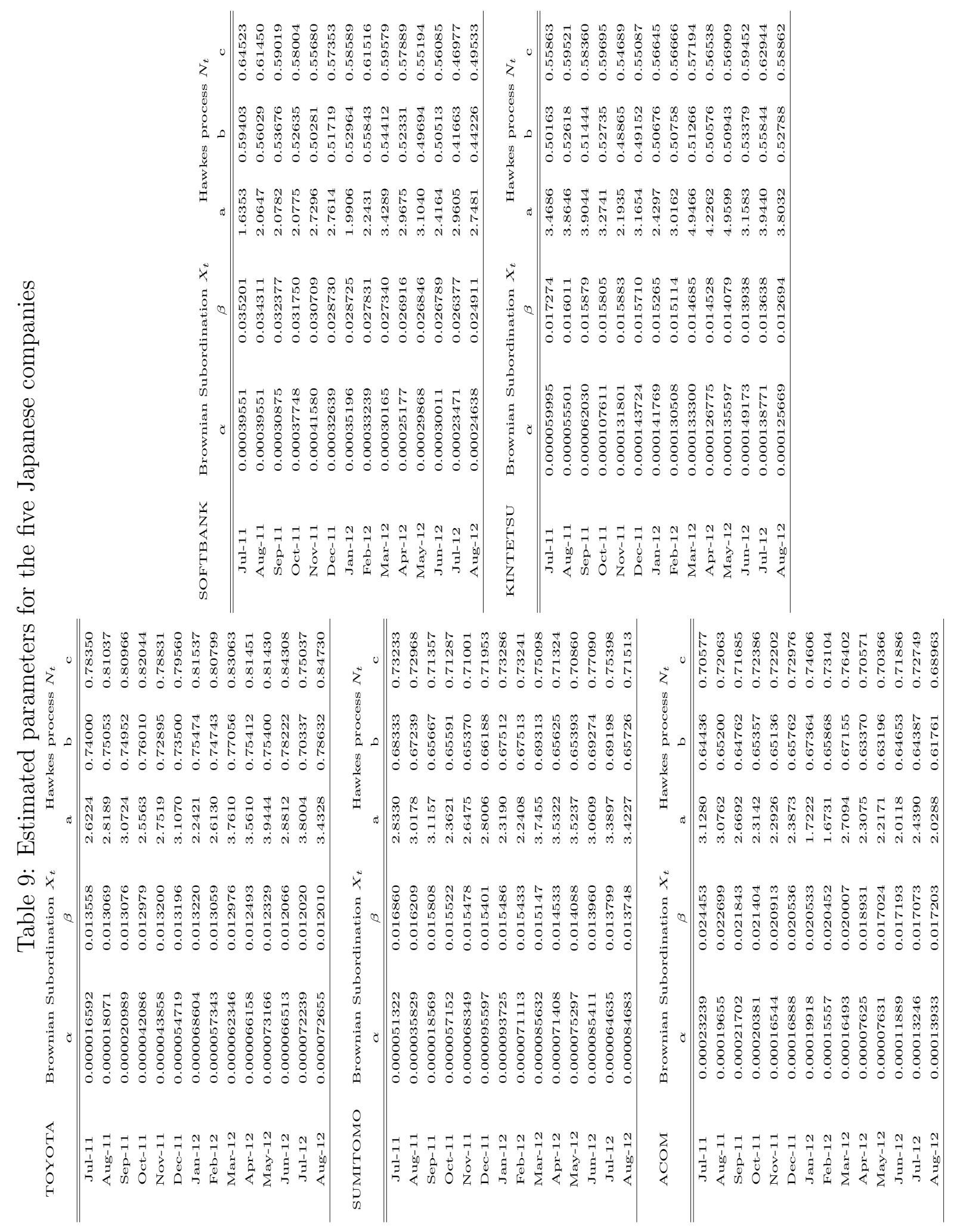




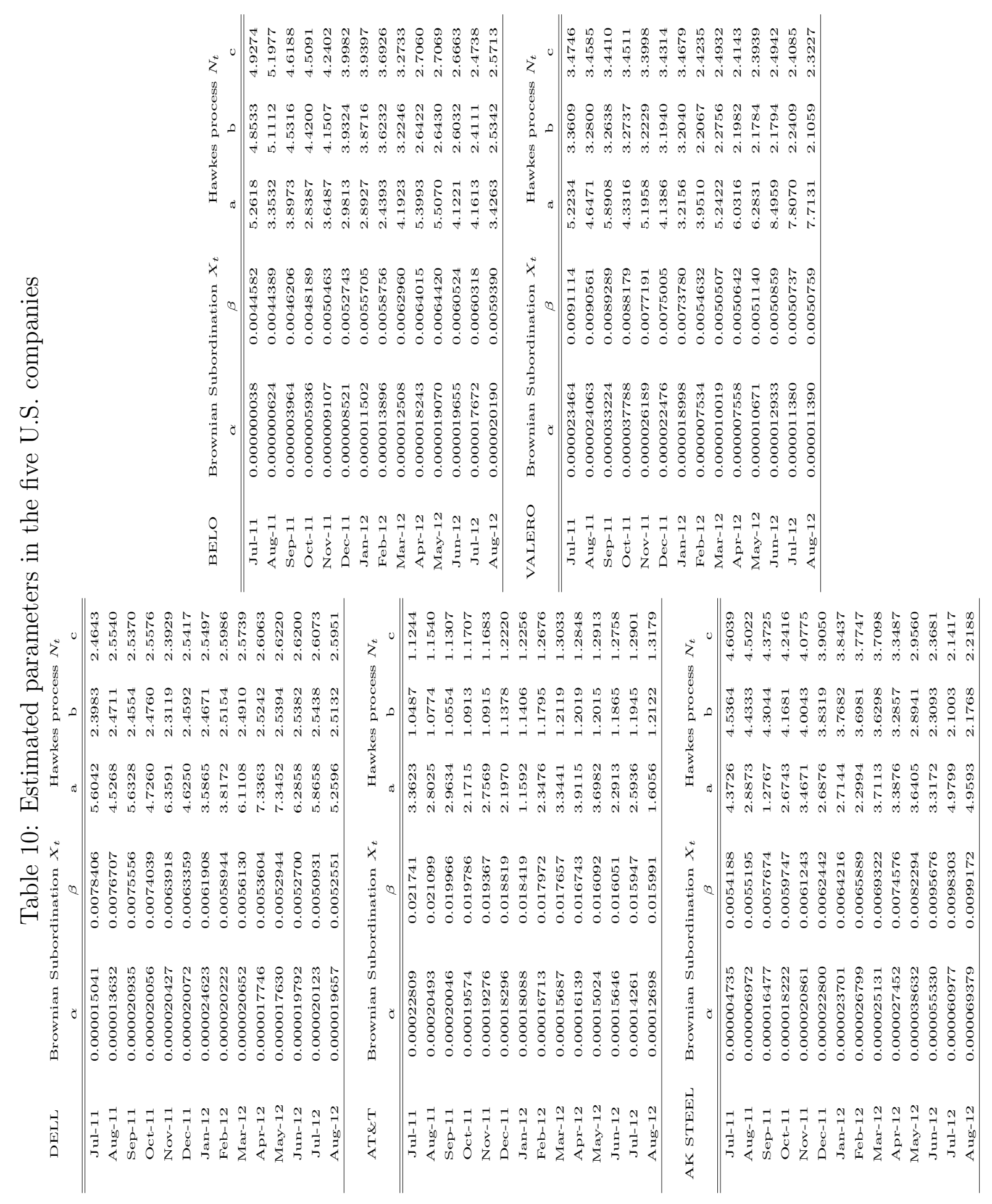




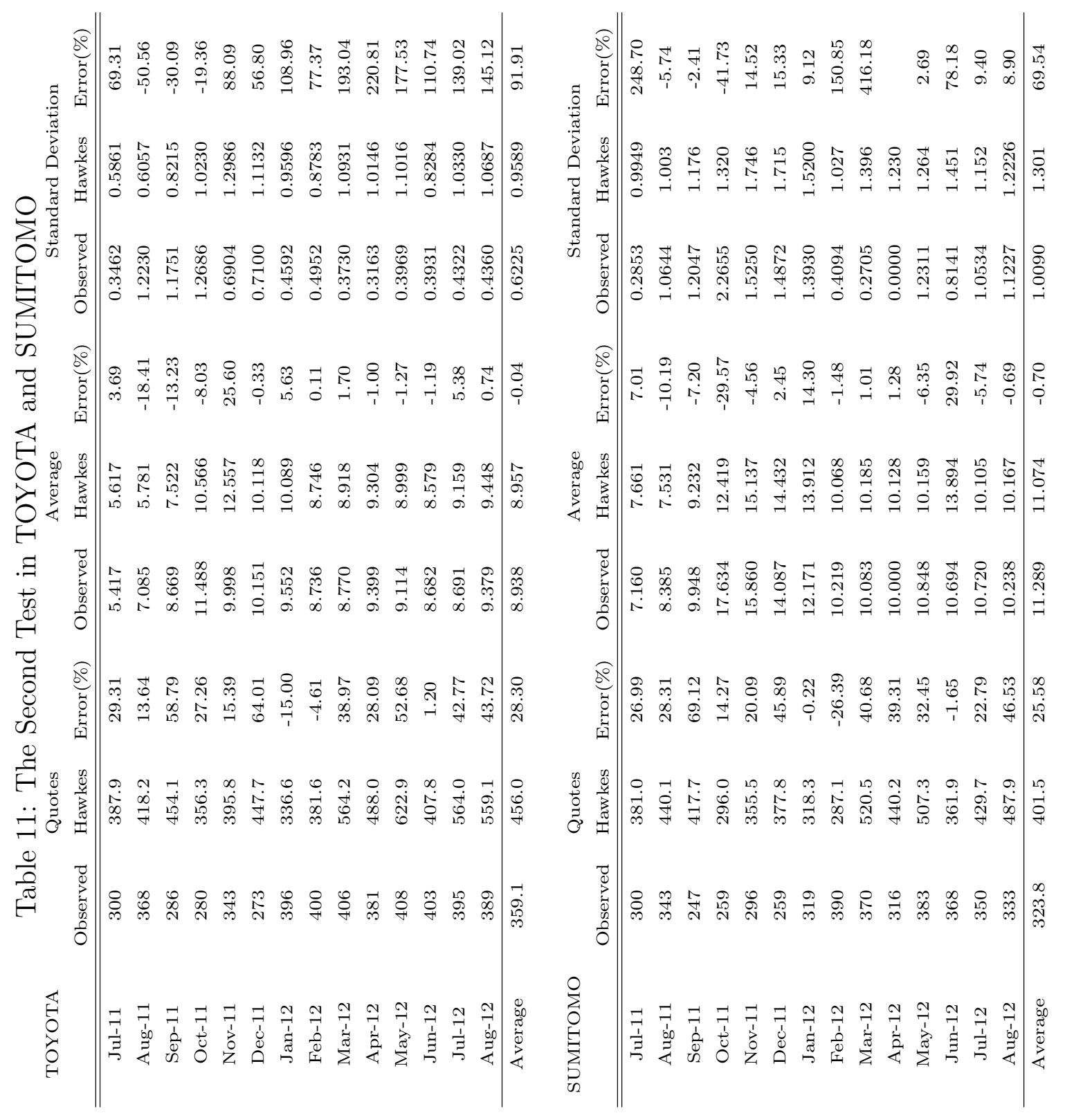




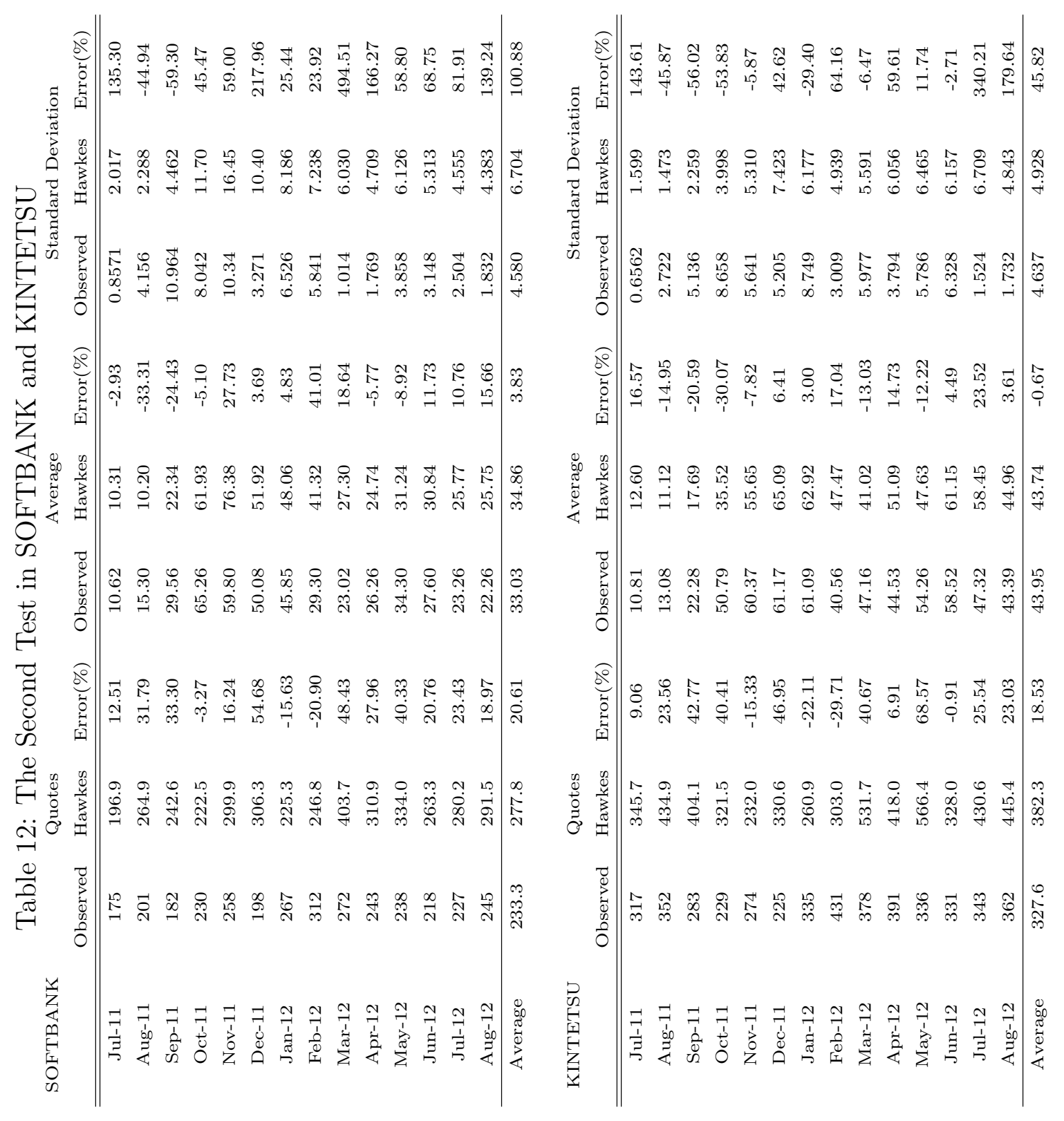




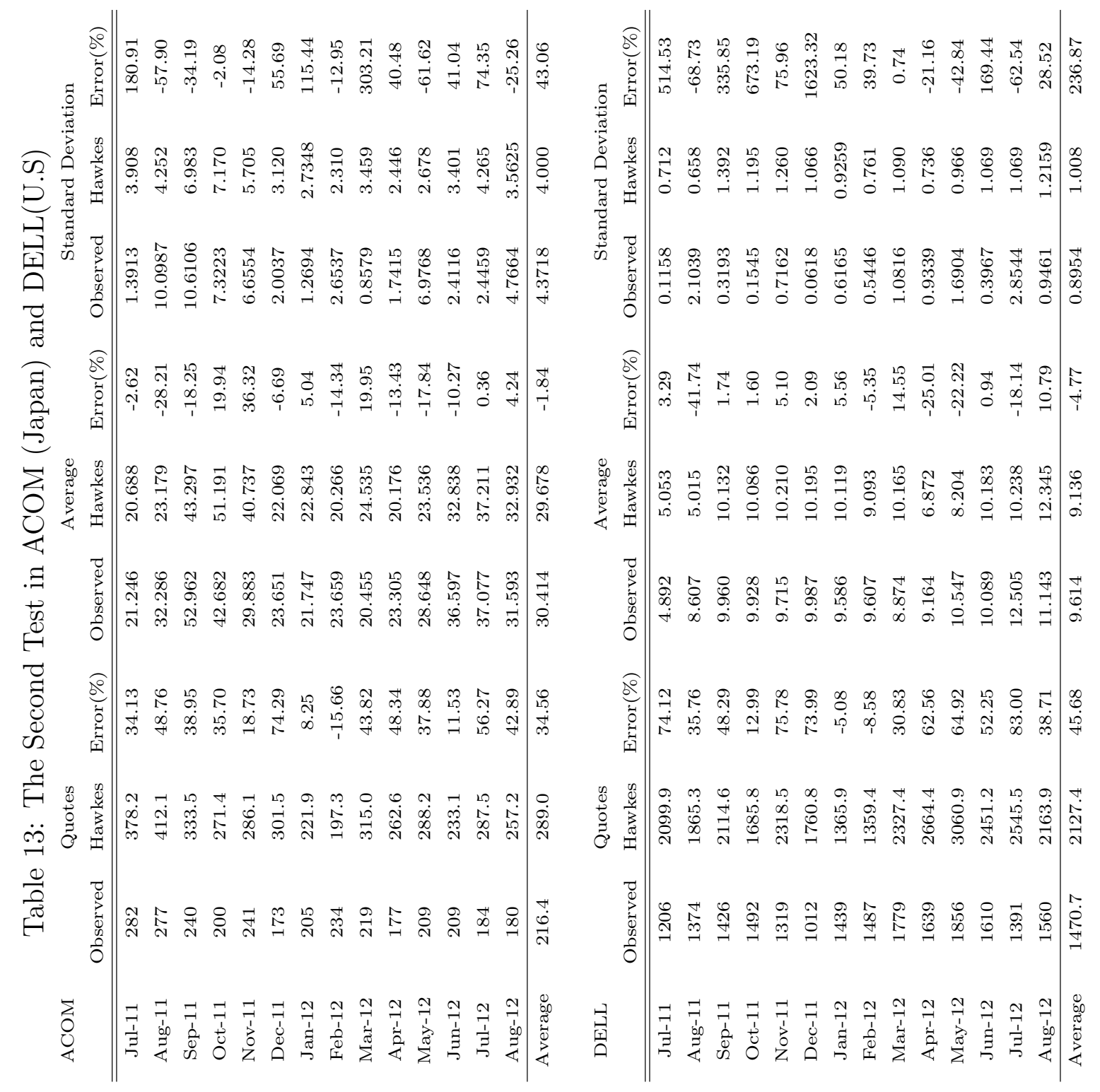




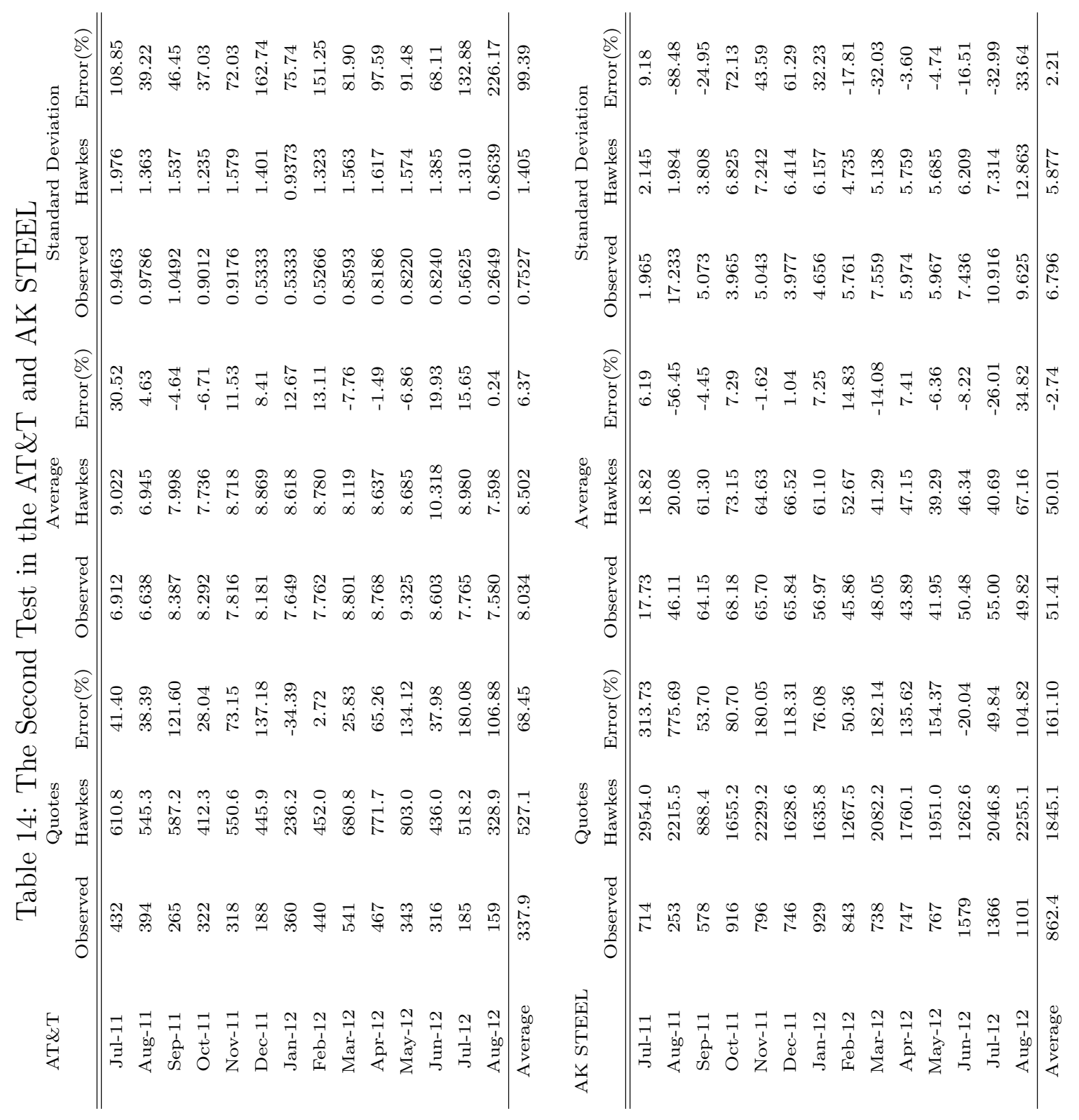




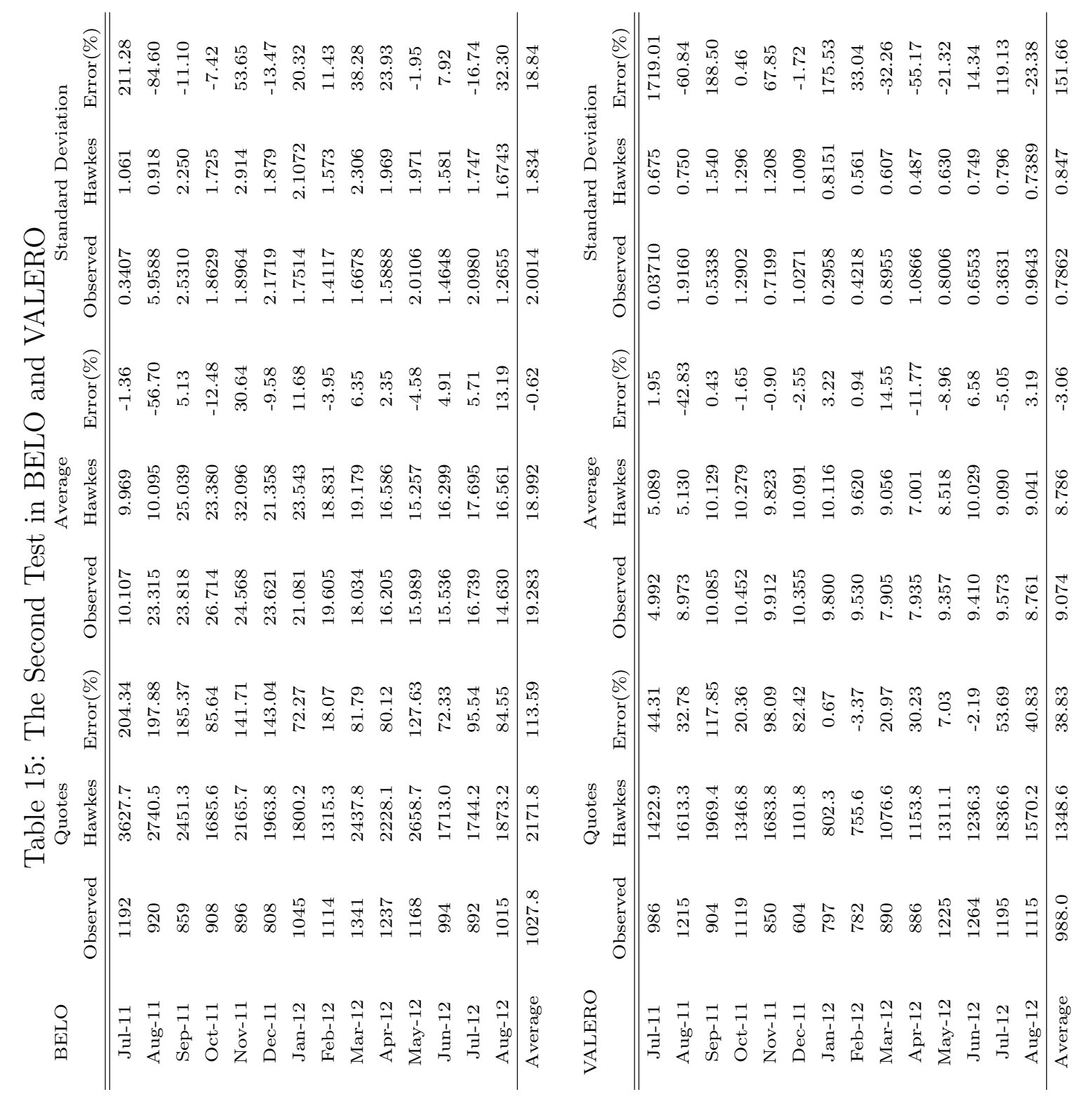




\section{References}

[1] V.V. Acharya and T.C. Johnson. Insider trading in credit derivatives. J. Financial Economics, 84:110-141, 2007.

[2] R. Blanco, S. Brennan, and I.W. Marsh. An empirial analysis of the dynamic relationship between investment-grade bonds and credit defalut swaps. J. Finance, 60:2255-2281, 2005.

[3] W. Bühler and M. Trapp. Time-varying credit risk and liquidity premia in bond and CDS markets. Working Paper;, http://econstor.eu/bitstream/10419/41349/1/616612656.pdf, 2009.

[4] E. Çinlar. Probability and Stochastics. Springer, 2011.

[5] R. F. Engle. Dynamic conditional correlation: A simple class of multivariate GARCH models. J. of Business and Economic Statistics, 20:339-350, 2002.

[6] J. Ericsson and O. Renault. Liquidity and credit risk. J. Finance, 61:2219-2250, 2006.

[7] E. Errais, K. Giesecke, and L.R.Goldberg. Affine point processes and portfolio credit risk. SIAM J. Financial Math., 1:642-665, 2010.

[8] A.G. Hawkes. Spectra of some self-exciting and mutually exciting point processes. Biometrika, 58:83-90, 1971.

[9] P. Hewlett. Clustering of order arrivals, price impact and trade path optimisation. Working Paper; http://users.iems.northwestern.edu/ armbruster/2007msande444/Hewlett2006\%20price\%20impact.pdf, 2006.

[10] F.A. Longstaff, S. Mithal, and E. Neis. Corporate yield spreads: default risk or liquidity? New evidende from the credit-default swap market. J. Finance, 60:2213-2253, 2005.

[11] L. Norden and M. Weber. The comovement of credit default swap, bond and stock markets: An empirical analysis. European Financial Management, 15:529-562, 2009.

[12] Y. Ogata. On Lewis' simulation method for point processes. IEEE Transactions on Information Theory, 27:23-31, 1981.

[13] D. O'Kane. Modelling single-name and multi-name credit derivatives. John Wiley \& Sons, England, 2008. 
[14] T. Ozaki. Maximum likelihood estimation of Hawkes' self-exciting point processes. Ann. Inst. Statist. Math. Part B, 31:145-155, 1979.

[15] R. Roll. A simple implicit measure of the effective bid-ask spread in an efficient market. Journal of Finance, 39(4):1127-1139, 1984. 